\title{
COMPARACIÓN DE LOS NIVELES DE RUIDO, NORMATIVA Y GESTIÓN DE RUIDO AMBIENTAL EN LIMA Y CALLAO RESPECTO A OTRAS CIUDADES DE LATINOAMÉRICA
}

\author{
Héctor Guillermo Gamero Motta \\ Investigador independiente
}

\begin{abstract}
Resumen: Debido al vertiginoso crecimiento económico, demográfico y a las constantes migraciones a la capital, Lima se ha convertido en un conglomerado de focos donde el ruido sobrepasa los niveles recomendados por la OMS. De ahí la importancia de hacer un análisis del ruido en la capital, con el fin de compararlo con otros países y estudiar la normativa que regula la contaminación acústica, para así dar a conocer las razones por las cuales la problemática del ruido debe ser solucionada. De la comparación hecha entre las ciudades elegidas (Lima, Bogotá y Santiago), se determinó que el ruido en Santiago es menor y está mejor controlado que en Lima y Bogotá, mientras que estos dos comparten realidades similares respecto a niveles de ruido. En el marco legal, los tres países tienen un sólido sistema normativo, pero en el caso del Perú, este empezó al menos una década tarde, ya que Chile y Colombia empezaron a preocuparse por ese problema desde los noventa. Es más, Chile sigue llevando la ventaja ya que posee un plan de gestión del ruido ambiental en donde expone medidas para su control. Todos estos factores hacen sentido en que la sociedad chilena está más a la vanguardia en temas de gestión de la contaminación acústica que la peruana, y su realidad se alinea más a los países referentes en acústica en el mundo.

Bajo este modelo, es importante que las autoridades reflexionen sobre la problemática ambiental del ruido y puedan tomar como punto de partida el análisis brindado en este estudio para una mejor gestión del ruido ambiental en Lima y el resto del Perú.
\end{abstract}

Palabras clave: acústica ambiental, ruido, contaminación acústica, mapa de ruido, Lima. 


\title{
Comparison of Noise Levels, Legal Framework and Environmental Noise Management in Lima and Callao with Regard to other Latin-American Cities
}

\begin{abstract}
Given the unbalanced urban development, the rapid economic growth and the various migrations toward the capital, Metropolitan Lima has become in a chaotic center where noise surpass the recommended exposure levels given from the WHO. Because of that, it has been decided to analyze noise in the capital in order to compare the results with other countries and to study the law that regulates noise pollution and finally to discover the reasons why noise is a problem to be solved. The comparison between Lima, Bogotá and Santiago concludes that noise levels in Santiago are lower and better controlled than Lima and Bogotá, while these ones share almost the same reality in terms of noise levels. Talking about legal framework, each country has an appropriate normative system, but in the case of Perú the legal framework began at least 10 years late because Chile and Colombia had started at the nineties. Furthermore, Chile keeps one step ahead due to its environmental noise management plan in which exposes mitigation solutions. According to all of these factors, make sense that Chilean society is in the state of the art in terms of managing noise pollution than ours and its reality is more alike to a country with high expertise in acoustics in the world.

Following this model, it is important that our authorities think clearly about noise pollution and take as a kick-off the analyze in this study to improve the environmental noise management in Lima and Peru.
\end{abstract}

Keywords: Environmental Acoustics, Noise, Noise Pollution, Noise Map, Lima.

\section{Héctor Guillermo Gamero Motta}

Estudiante de ingeniería civil cursando el 10 mo ciclo en la PUCP, con experiencia en el análisis estructural para empresas de distintos rubros, como: salud, minería, construcción y entidades del Estado. Principal interés en el control de ruido y la acústica ambiental, a fin de lograr un buen desempeño a nivel de estructuras y de acústica arquitectónica. Participó en diversos voluntariados de la universidad, entre ellos ser el director de Logística y Finanzas en la asociación estudiantil GESCON (Gestión y Construcción). Actualmente es miembro de la empresa de consultoría estructural CGM Servicios Generales. 
COMPARACIÓN DE LOS NIVELES DE RUIDO, NORMATIVA Y GESTIÓN DE RUIDO AMBIENTAL EN LIMA Y CALlaO RESPECTO A OTRAS CIUdAdES DE LATINOAMÉRICA / HÉCTOR GUILlERMo GAMERo MotTA

\section{Introducción}

El ruido, entendido - aunque no restringido- como cualquier sonido no deseado (OMS 1999), es un factor que impacta negativamente en la sociedad en el día a día. En un contexto más amplio, se desprende el concepto de contaminación acústica, que a su vez se disgrega en ruido ambiental o urbano (tráfico rodado, aéreo, a rieles, artefactos domésticos u otro tipo de eventos recreacionales) y ruido ocupacional (actividades industriales, principalmente). Los ruidos con altos niveles de presión sonora generan malestar y daños a la salud tales como dolencias cardiovasculares, molestia en los oídos, problemas de sueño, pérdida de la audición, déficit cognitivo, entre otros (OMS 1999). En la tabla 1 se muestran los efectos que tiene el ruido en distintos ambientes según el nivel de ruido y un tiempo de exposición que es lo mínimo necesario para generar malestar crítico a la salud.

Para fines de análisis, se estudiará el nivel de presión sonora, el cual indica cuán intenso se percibe el ruido y se cuantifica mediante la unidad dB (OEFA 2016). De esta manera se cuantifica el nivel de presión sonora que se propaga a través de un medio elástico, como el aire, por ejemplo. A través de este medio las perturbaciones moleculares llegan al pabellón de la oreja y por el sistema auditivo se transmiten al cerebro donde se perciben dichas perturbaciones como sonido y son registradas como sonoridad (debido a características físicas y fisiológicas) (Moreno 1990). Es por esta razón que la manera de cuantificar el sonido que capta una persona es mediante la ponderación A (que expresa sonoridad) (OMS 2004) y es el valor que se usará para referirse al ruido al que está expuesto la ciudadanía. Por ejemplo, según la OMS en el texto Guías para el ruido urbano (1999), un nivel aceptable de ruido al aire libre es de $55 \mathrm{~dB}(\mathrm{~A})$ en horario diurno antes de que signifique la molestia de la persona. Sin embargo, es importante recalcar que para que se produzca la pérdida gradual de la audición se definen estándares que dependen de dos variables: la magnitud del ruido y el tiempo de exposición. En Estados Unidos, diversas entidades de salud y protección ambiental han estudiado estos parámetros para determinar valores máximos permitidos de exposición respecto a un nivel de ruido. En la tabla 2 se muestran estos valores, siendo la tercera elaborada en conjunto por la Organización Mundial de 
la Salud (OMS) y la Agencia de Protección Ambiental (EPA) de los Estados Unidos, la que se tomará como referencia internacional para compararla con la normativa de los países a estudiar ya que muestra valores más conservadores.

Tabla 1.

Efectos críticos sobre la salud según el tipo de ambiente

\begin{tabular}{|c|c|c|c|}
\hline Ambiente específico & $\begin{array}{c}\text { Efecto(s) crítico(s) sobre la } \\
\text { salud }\end{array}$ & $\begin{array}{l}\text { Laeq,T } \\
\mathrm{dB}(\mathrm{A})\end{array}$ & $\begin{array}{l}\text { Tiempo } \\
\text { (horas) }\end{array}$ \\
\hline Exteriores & $\begin{array}{c}\text { Molestia grave en el día y el } \\
\text { anochecer Molestia moderada } \\
\text { en el día y anochecer }\end{array}$ & $\begin{array}{l}55 \\
50\end{array}$ & $\begin{array}{l}16 \\
16\end{array}$ \\
\hline $\begin{array}{l}\text { Interior de la vivienda, } \\
\text { dormitorios }\end{array}$ & $\begin{array}{c}\text { Interferencia en la } \\
\text { comunicación oral y molestia } \\
\text { moderada en el día y al } \\
\text { anochecer Trastorno del } \\
\text { sueño durante la noche }\end{array}$ & $\begin{array}{l}35 \\
30\end{array}$ & $\begin{array}{c}16 \\
8\end{array}$ \\
\hline Fuera de los dormitorios & $\begin{array}{l}\text { Trastorno del sueño, ventana } \\
\text { abierta (valores en exteriores) }\end{array}$ & 45 & 8 \\
\hline $\begin{array}{l}\text { Sala de la clase e interior de } \\
\text { los centros preescolares }\end{array}$ & $\begin{array}{c}\text { Interferencia en la } \\
\text { comunicación oral, disturbio } \\
\text { en el análisis de información y } \\
\text { comunicación del mensaje }\end{array}$ & 35 & $\begin{array}{l}\text { Durante } \\
\text { clases }\end{array}$ \\
\hline $\begin{array}{l}\text { Dormitorios de centros } \\
\text { preescolares, interiores }\end{array}$ & Trastorno del sueño & 30 & $\begin{array}{c}\text { Durante } \\
\text { el } \\
\text { descanso }\end{array}$ \\
\hline $\begin{array}{c}\text { Escuelas, áreas exteriores } \\
\text { de juego }\end{array}$ & Molestia (fuentes externas) & 55 & $\begin{array}{l}\text { Durante } \\
\text { el juego }\end{array}$ \\
\hline $\begin{array}{l}\text { Hospitales, pabellones, } \\
\text { interiores }\end{array}$ & $\begin{array}{l}\text { Trastorno del sueño durante } \\
\text { la noche Trastorno del sueño } \\
\text { durante el día y al anochecer }\end{array}$ & $\begin{array}{l}30 \\
30\end{array}$ & $\begin{array}{c}8 \\
16\end{array}$ \\
\hline $\begin{array}{l}\text { Hospitales, salas de } \\
\text { tratamiento, interiores }\end{array}$ & $\begin{array}{c}\text { Interferencia en el descanso y } \\
\text { la recuperación }\end{array}$ & $\begin{array}{l}\text { Lo más bajo } \\
\text { posible }\end{array}$ & \\
\hline $\begin{array}{l}\text { Áreas industriales, } \\
\text { comerciales y de tránsito, } \\
\text { interiores y exteriores }\end{array}$ & Deficiencia auditiva & 70 & 24 \\
\hline $\begin{array}{l}\text { Ceremonias, festivales y } \\
\text { eventos de entretenimiento }\end{array}$ & $\begin{array}{l}\text { Deficiencia auditiva (no más } \\
\text { de } 5 \text { veces al año) }\end{array}$ & 100 & 4 \\
\hline $\begin{array}{l}\text { Discursos públicos, } \\
\text { interiores y exteriores }\end{array}$ & Deficiencia auditiva & 85 & 1 \\
\hline $\begin{array}{l}\text { Música y otros sonidos } \\
\text { a través de audífonos o } \\
\text { parlantes }\end{array}$ & $\begin{array}{l}\text { Deficiencia auditiva (valor de } \\
\text { campo libre) }\end{array}$ & $\begin{array}{l}85 \text { (valor } \\
\text { a campo } \\
\text { libre) }\end{array}$ & 1 \\
\hline $\begin{array}{l}\text { Exteriores de parques } \\
\text { de diversión y áreas de } \\
\text { conservación }\end{array}$ & $\begin{array}{l}\text { Interrupción de la } \\
\text { tranquilidad }\end{array}$ & $\begin{array}{c}\text { Se debe } \\
\text { preservar la } \\
\text { tranquilidad }\end{array}$ & \\
\hline
\end{tabular}


COMPARACIÓN DE LOS NIVELES DE RUIDO, NORMATIVA Y GESTIÓN DE RUIDO AMBIENTAL EN LIMA Y CALLAO RESPECTO A OTRAS CIUDAdES DE LATINOAMÉRICA / HÉCTOR GUILlERMo GAMERo MotTA

Tabla 2.

Tiempo de exposición permitido para niveles de ruido según diferentes estándares internacionales

\begin{tabular}{|c|c|c|c|c|c|c|c|}
\hline & \multicolumn{5}{|c|}{ Tiempo de exposición (min) } \\
\hline Estándares internacionales & $\mathbf{7 5}$ & $\mathbf{8 5}$ & $\mathbf{9 0}$ & $\mathbf{1 0 0}$ & $\mathbf{1 0 5}$ & $\mathbf{1 1 5}$ \\
\hline $\begin{array}{c}\text { OSHA: Administración de } \\
\text { Seguridad y Salud Ocupacional }\end{array}$ & $>24 \mathrm{~h}$ & 960 & 480 & 120 & 60 & 15 \\
\hline $\begin{array}{c}\text { NIOSH: Instituto Nacional para la } \\
\text { Seguridad y Salud Ocupacional }\end{array}$ & $>24 \mathrm{~h}$ & 480 & 151 & 15 & 4,5 & 0,5 \\
\hline $\begin{array}{c}\text { OMS y EPA: Agencia de Protección } \\
\text { Ambiental }\end{array}$ & 480 & 47,5 & 15 & 15 & 0,5 & 0 \\
\hline
\end{tabular}

Fuente: Extraído de Ghotbi et al. (2011: s/p).

Con el propósito de la medición de ruido se definen los horarios diurno y nocturno. En Perú, el horario diurno corresponde a un periodo comprendido desde las 07:01 horas hasta las 22:00, mientras que desde las 22:01 horas hasta las 07:00 horas del día siguiente le corresponde al horario nocturno. Otro término a definir es el nivel de presión sonora continuo equivalente con ponderación A (LAeq,T), el cual es el nivel de presión sonora constante expresado en decibeles A, que en el mismo intervalo de tiempo (T) contiene la misma energía total que el sonido medido (MINAM 2003).

Con el objetivo de controlar la contaminación sonora se definen los ECA como Estándares de Calidad Ambiental, los cuales establecen el nivel de concentración de elementos o sustancias presentes en el aire, agua o suelo que no representa un riesgo significativo para la salud de las personas o el ambiente (OEFA 2015). De esta forma es posible diseñar normas legales y políticas públicas en beneficio de la sociedad. En la tabla 3 se muestran los ECA de ruido:

Tabla 3.

Estándares de Calidad Ambiental para ruido en el Perú por zona de aplicación

\begin{tabular}{|l|c|c|}
\multicolumn{1}{c|}{ Zona de aplicación } & \multicolumn{2}{|c}{ Valores expresados: (LAeq,T) } \\
\hline Zona de protección especial & $50 \mathrm{~dB}$ & Horario nocturno \\
\hline Zona residencial & $60 \mathrm{~dB}$ & $40 \mathrm{~dB}$ \\
\hline Zona comercial & $70 \mathrm{~dB}$ & $50 \mathrm{~dB}$ \\
\hline Zona industrial & $80 \mathrm{~dB}$ & $60 \mathrm{~dB}$ \\
\hline
\end{tabular}

Fuente: Extraído de OEFA (2015: 26). 
Para medir estos niveles de presión sonora se usa el sonómetro, el cual debe estar calibrado por entidades acreditadas ante Indecopi, para asegurar que los resultados sean utilizados como sustento de que siguieron los estándares y pueda ser comparado y replicado en otros estudios, además de que dichas mediciones se rigen por normas técnicas peruanas de acústica y medición de ruido ambiental (OEFA 2015).

En relación con la zona de aplicación y la actividad realizada, se realiza un monitoreo del ruido ambiental, en el cual se evalúa el impacto del ruido en el entorno y con los resultados se pueden generar mapas de ruido para su posterior análisis. El Perú, siendo un país alineado al contexto global y siguiendo las recomendaciones que la OMS emite en relación a la contaminación en general, posee entidades que regulan, en este caso en específico, el ruido a lo largo y ancho del país. Estas entidades son: el Ministerio del Ambiente (MINAM), las municipalidades distritales y provinciales, el Instituto Nacional de Calidad (Inacal), el Organismo de Evaluación y Fiscalización Ambiental (OEFA), el Ministerio de Salud (MINSA), Indecopi, entre otros. Sin embargo, es de conocimiento público que la situación de Lima, en particular, es alarmante ya que el ruido forma parte de la vida de comerciantes, transeúntes, conductores, escolares, etcétera, que no son conscientes del daño al cual están sometidos día tras día.

Esta realidad obliga a cuestionar por qué el ruido supone un problema a pesar de que existan entes reguladores y fiscalizadores para este fenómeno.

Una guía más reciente sobre el impacto del ruido ambiental en las ciudades de Europa (WHO 2018) da una mirada integral de todas las diferentes fuentes de ruido que inciden en el bienestar de las personas y brinda una serie de recomendaciones en materia de niveles de emisión de ruido que pueden ser aplicables no solo en esa región, sino también en otras partes del mundo como América Latina. En la tabla 4 se muestran estos valores máximos recomendados (Tabla 4).

Vale añadir que estos valores solo indican los niveles que las fuentes emiten y que son los recomendados para no generar efectos negativos contra la salud, pero el ruido que es percibido por las personas es la suma de varias fuentes y lo que se toma en cuenta para asegurar su bienestar es lo indicado en las tablas 1 y 2 . 
COMPARACIÓN DE LOS NIVELES DE RUIDO, NORMATIVA Y GESTIÓN DE RUIDO AMBIENTAL EN LIMA Y CALlaO RESPECTO A OTRAS CIUdAdES DE LATINOAMÉRICA / HÉCTOR GUILlERMo GAMERo MotTA

Tabla 4.

Valores de ruido límite recomendados por la OMS en función a la fuente

\begin{tabular}{|c|c|c|}
\hline Tipo de fuente & Periodo & Valor límite de ruido (dBA) \\
\hline \multirow{2}{*}{ Tráfico vehicular } & día & 53 \\
\cline { 2 - 3 } & noche & 45 \\
\hline \multirow{2}{*}{ Ruido ferroviario } & día & 54 \\
\cline { 2 - 3 } & noche & 44 \\
\hline \multirow{2}{*}{ Ruido aéreo } & día & 45 \\
\hline \multirow{2}{*}{ Ruido de aerogeneradores } & noche & 40 \\
\cline { 2 - 3 } & día & 45 \\
\hline Ruido por ocio & noche & No aplica \\
\hline
\end{tabular}

Fuente: WHO (2018: xvi y xviii). Elaboración propia.

A continuación, se analiza el reporte que emitió la OEFA en 2016 acerca del ruido en las ciudades de Lima y Callao para validar lo dicho anteriormente.

\section{La contaminación sonora en Lima y Callao}

Lima Metropolitana (entendida como el área conformada por Lima y Callao) es la zona urbana más extensa y poblada del Perú y está entre las ciudades con mayor densidad poblacional de América del Sur, motivo por el cual su análisis es un referente para compararlo con otras realidades en la región. La figura 1 muestra la distribución de Lima Metropolitana.

En las ciudades de Lima y Callao, la Dirección de Evaluación del OEFA, ente rector del Sistema de Evaluación y Fiscalización ambiental, realizó dos campañas para medir el ruido y ver si la salud de la población estaba siendo afectada. La primera en el año 2013 y la segunda en 2015. Para fines de este informe se tomará en cuenta el último estudio por ser el más cercano a las condiciones actuales.

Se tomaron 250 puntos entre los 49 distritos que conforman ambas provincias, midiendo los niveles de presión sonora equivalente mediante un sonómetro. El horario de las mediciones fue diurno y se buscó que sea en el momento del día donde hubiera mayor tráfico vehicular. Cabe resaltar que cada periodo de medición fue de 60 minutos por punto. De esta forma los valores indican nivel de presión sonora continuo equivalente con ponderación A (LAeq,T) en ese periodo de tiempo. 
Figura 1.

Ordenamiento territorial de Lima Metropolitana
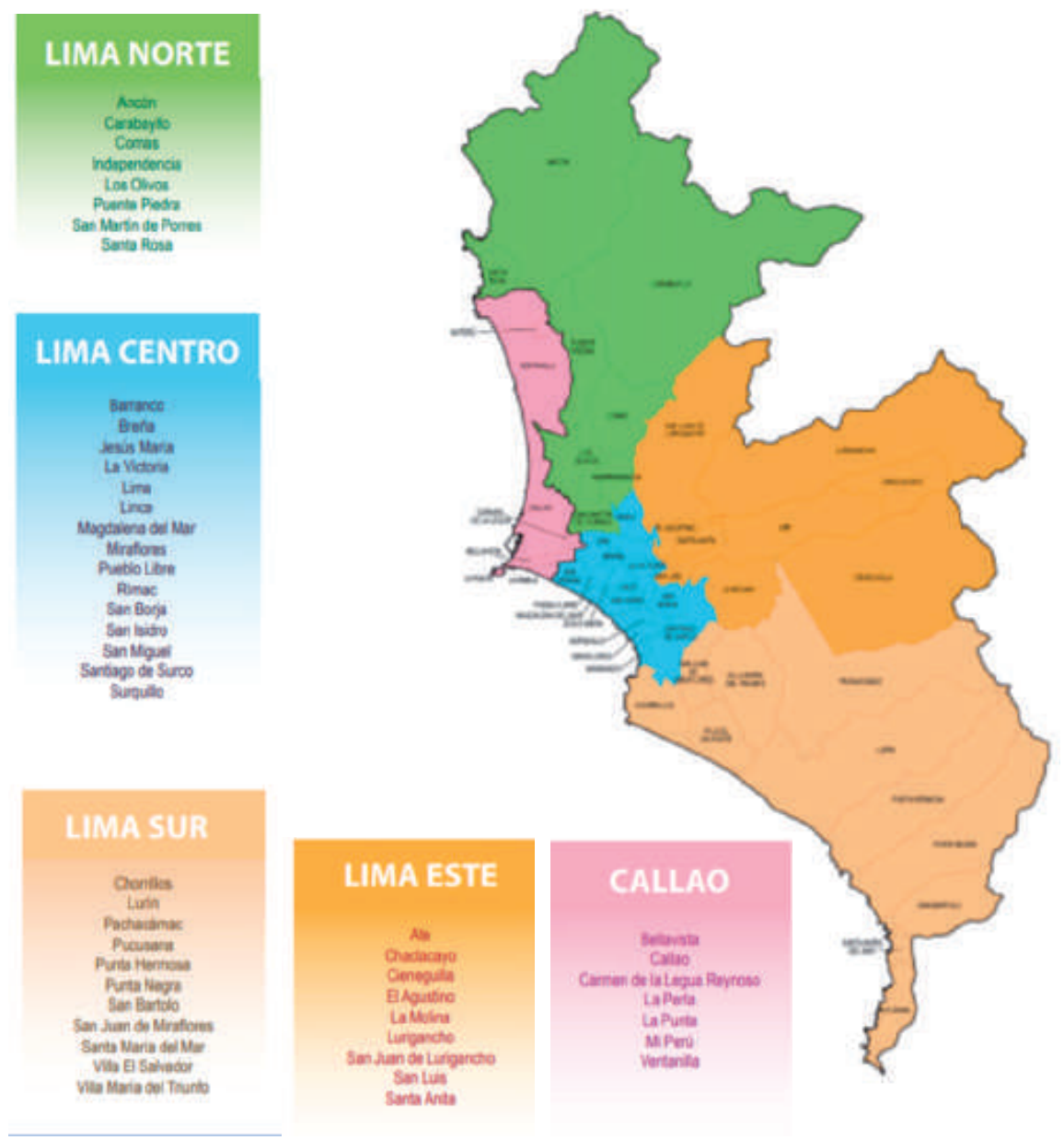

Fuente: Extraído de INEI (2014: 9).

\subsection{Lima}

Lima cuenta con una extensión de $2.672 \mathrm{~km}^{2}$ (Lima Cómo Vamos 2016) y en ese entonces la población superaba los 8,8 millones de habitantes (INEI 2008).

El parque automotor limeño superó los 1,7 millones de vehículos (como se indica en la tabla 5) y al 2025 será de más de 3 millones (Posada 2018). 
COMPARACIÓN DE LOS NIVELES DE RUIDO, NORMATIVA Y GESTIÓN DE RUIDO AMBIENTAL EN LIMA Y CALlaO RESPECTO A OTRAS CIUdAdES DE LATINOAMÉRICA / HÉCTOR GUILlERMo GAMERo MotTA

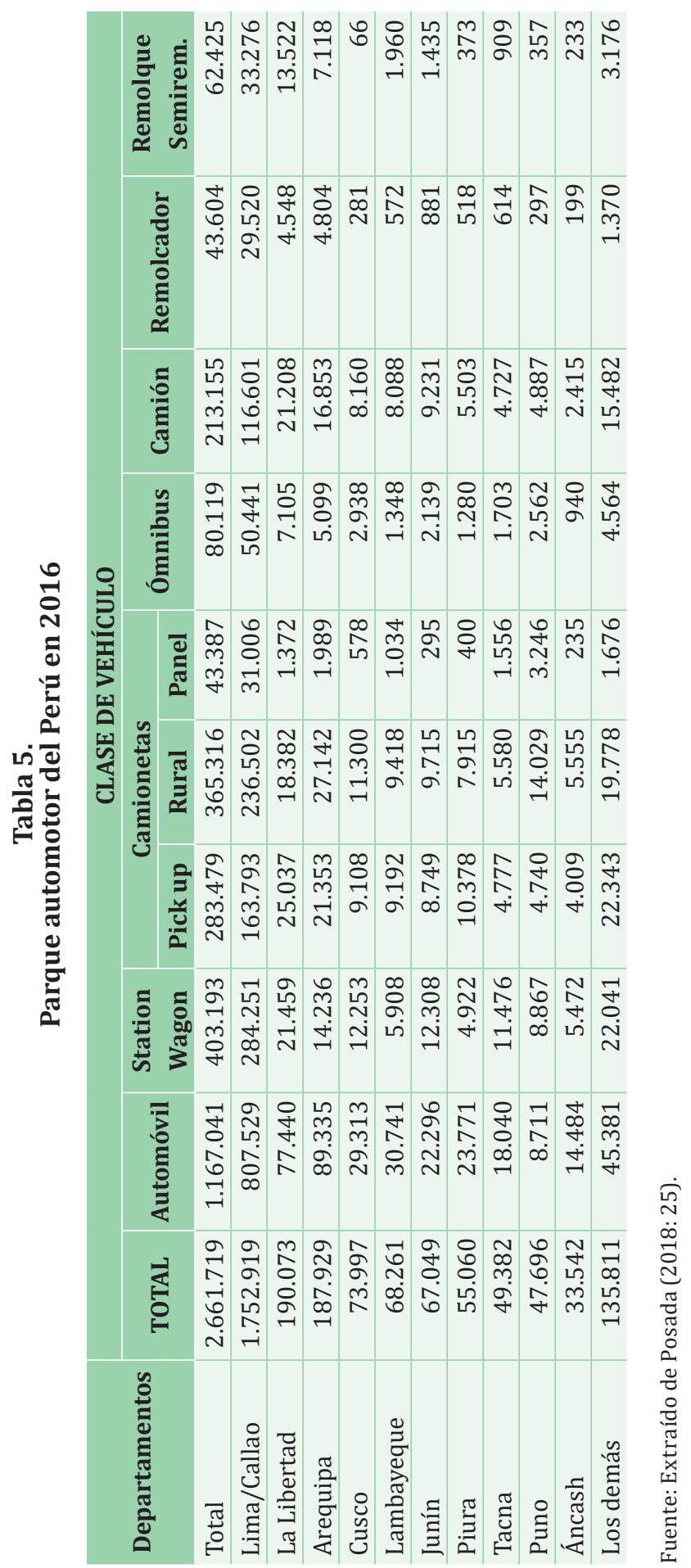


En Lima, se mostró que de los 224 puntos evaluados 194 podían catalogarse dentro de alguna zona de aplicación y de estos solo 19 no excedían los ECA del ruido. A continuación, en la figura 2 se muestran los puntos evaluados por zona de aplicación.

Figura 2.

Cantidad de puntos de medición por tipo de zona de aplicación que exceden los ECA de ruido en Lima

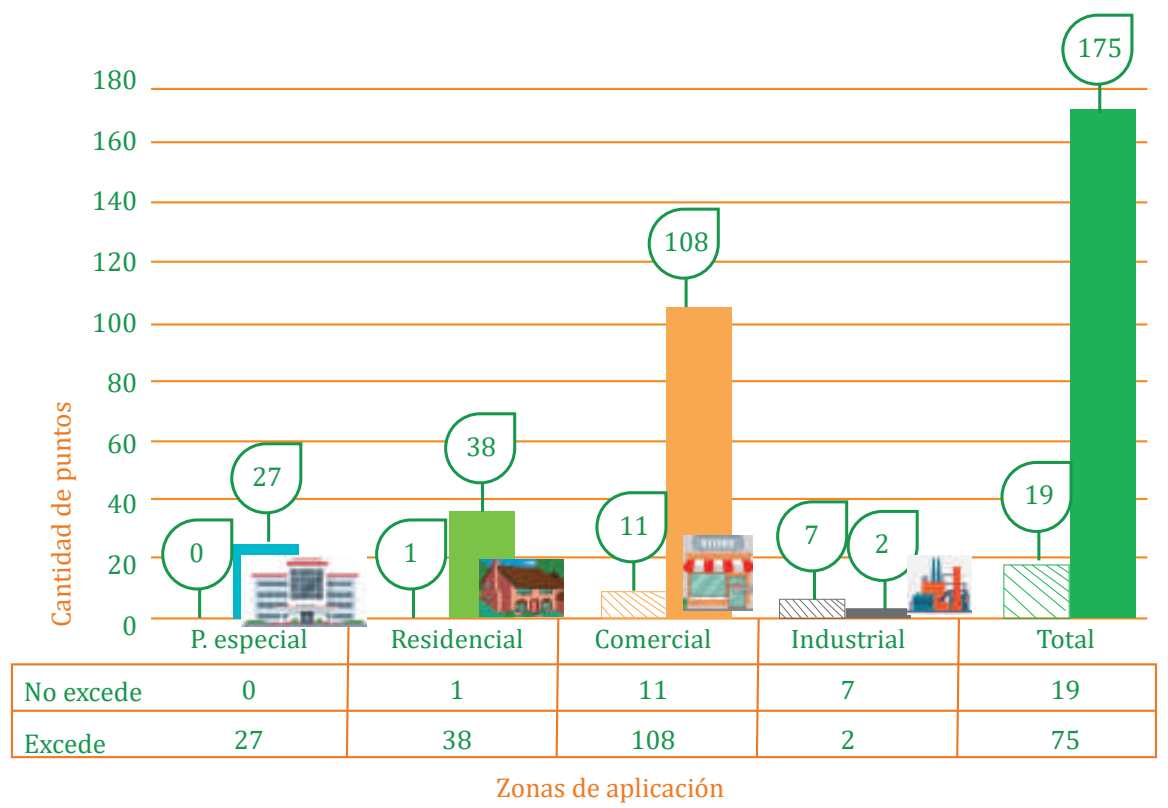

Fuente: Extraído de OEFA (2016: 36). 
COMPARACIÓN DE LOS NIVELES DE RUIDO, NORMATIVA Y GESTIÓN DE RUIDO AMBIENTAL EN LIMA Y CALlAo RESPECTO A OTRAS CIUdAdES DE LATINOAMÉRICA / HÉctor GUILLERMo GAMERo MotTA

Asimismo, los principales focos de ruido se muestran en la tabla 6:

Tabla 6.

Resultados de los 10 puntos de mayor nivel de presión sonora en Lima

\begin{tabular}{|c|c|c|c|c|c|c|}
\hline \multirow{2}{*}{$\mathbf{N}^{\mathbf{0}}$} & \multirow{2}{*}{ Distrito } & \multicolumn{2}{|c|}{ Punto de medición } & \multirow{2}{*}{ Descripción } & \multirow{2}{*}{$\begin{array}{c}\text { Zona de } \\
\text { aplicación }\end{array}$} & \multirow{2}{*}{$\begin{array}{l}\text { LAEQ,T } \\
\text { (dBA) }\end{array}$} \\
\hline & & Cod. RENIEC & Cod. OEFA & & & \\
\hline 1 & El Agustino & 149135-RUI-01 & 1369,RUI-01 & $\begin{array}{l}\text { Av.José Carlos } \\
\text { Mariátegui con Jr. } \\
\text { 1ero de Mayo }\end{array}$ & Comercial & 84,9 \\
\hline 2 & $\begin{array}{l}\text { Santiago de } \\
\text { Surco }\end{array}$ & 140130-RUI-05 & 1358,RUI-05 & $\begin{array}{l}\text { Av. Javier Prado } \\
\text { con Av. Manuel } \\
\text { Olguín }\end{array}$ & $\begin{array}{l}\text { Protección } \\
\text { Especial }\end{array}$ & 84,5 \\
\hline 3 & Ate & 140103-RUI-04 & 1372,RUI-04 & $\begin{array}{l}\text { Carretera Central } \\
\text { con calle La } \\
\text { Estrella }\end{array}$ & Comercial & 84,3 \\
\hline 4 & $\begin{array}{l}\text { San Martín } \\
\text { de Porres }\end{array}$ & 140126-RUI-01 & 1375,RUI-01 & $\begin{array}{l}\text { Panamericana } \\
\text { Norte frente a } \\
\text { Municipalidad } \\
\text { distrital de SMP }\end{array}$ & Comercial & 83 \\
\hline 5 & $\begin{array}{l}\text { Lurigancho } \\
\text { Chosica }\end{array}$ & 140112-RUI-06 & 1340,RUI-06 & $\begin{array}{l}\text { Av. Las Torres } \\
\text { con vía de acceso } \\
\text { a Carapongo }\end{array}$ & Comercial & 82,7 \\
\hline 6 & El Agustino & 140135-RUI-07 & 1369,RUI-07 & $\begin{array}{l}\text { Av. Rivaguero } \\
\text { cuadra } 13 \text { (Alt. de } \\
\text { la municipalidad } \\
\text { distrital de El } \\
\text { Agustino) }\end{array}$ & Comercial & 82,3 \\
\hline 7 & Carabayllo & 140105-RUI-03 & 1379,RUI-03 & $\begin{array}{l}\text { Av. Merino Reyna } \\
\text { con Av. Tupac } \\
\text { Amaru }\end{array}$ & Comercial & 82,2 \\
\hline 8 & $\begin{array}{c}\text { San Juan de } \\
\text { Miraflores }\end{array}$ & 140136-RUI-04 & 1351,RUI-04 & $\begin{array}{l}\text { Av. Los Héroes } \\
\text { con Av. San Juan }\end{array}$ & Comercial & 81,9 \\
\hline 9 & $\begin{array}{l}\text { Santiago de } \\
\text { Surco }\end{array}$ & 140130-RUI-06 & 1358,RUI-06 & $\begin{array}{l}\text { Av Santiago de } \\
\text { Surco con Av. } \\
\text { Próceres }\end{array}$ & Comercial & 81,8 \\
\hline 10 & Breña & 140104-RUI-02 & 1366,RUI-02 & $\begin{array}{l}\text { Av. Arica con } \\
\text { Plaza Bolognesi }\end{array}$ & ZTE & 81,6 \\
\hline
\end{tabular}

Fuente: Extraído de OEFA (2016: 37). [falta transcribir la tabla]

A continuación, se muestran los mapas de isófonas (líneas que delimitan igual nivel de presión sonora según colores) de los sectores de Lima: 
Figura 3.

Mapa de isófonas de Lima Centro

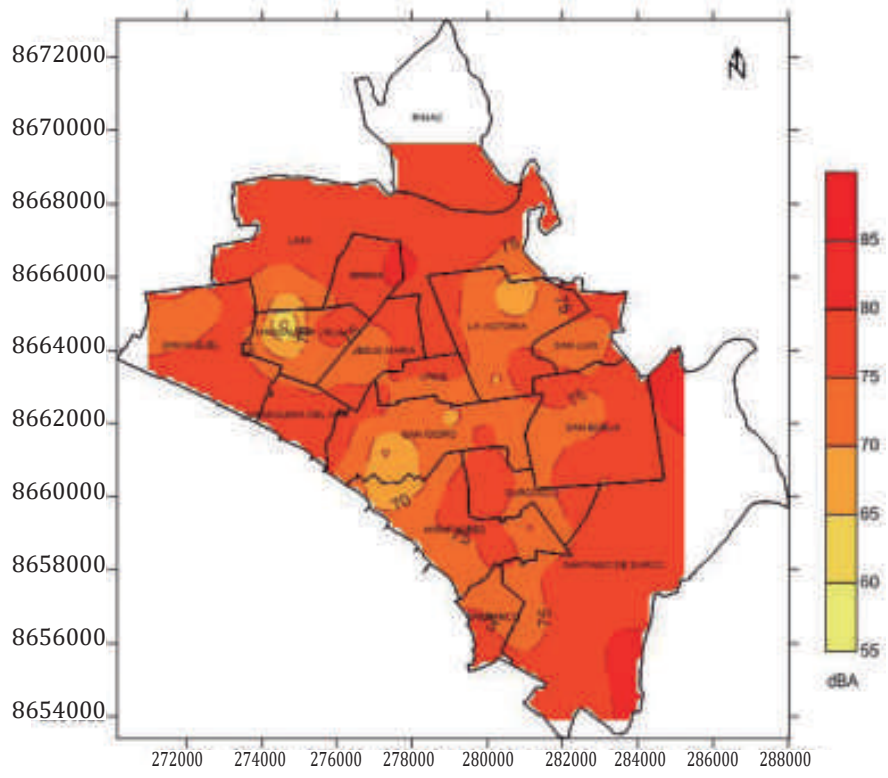

Fuente: Extraído de OEFA (2016: 39).

Figura 4.

Mapa de isófonas de Lima Este.

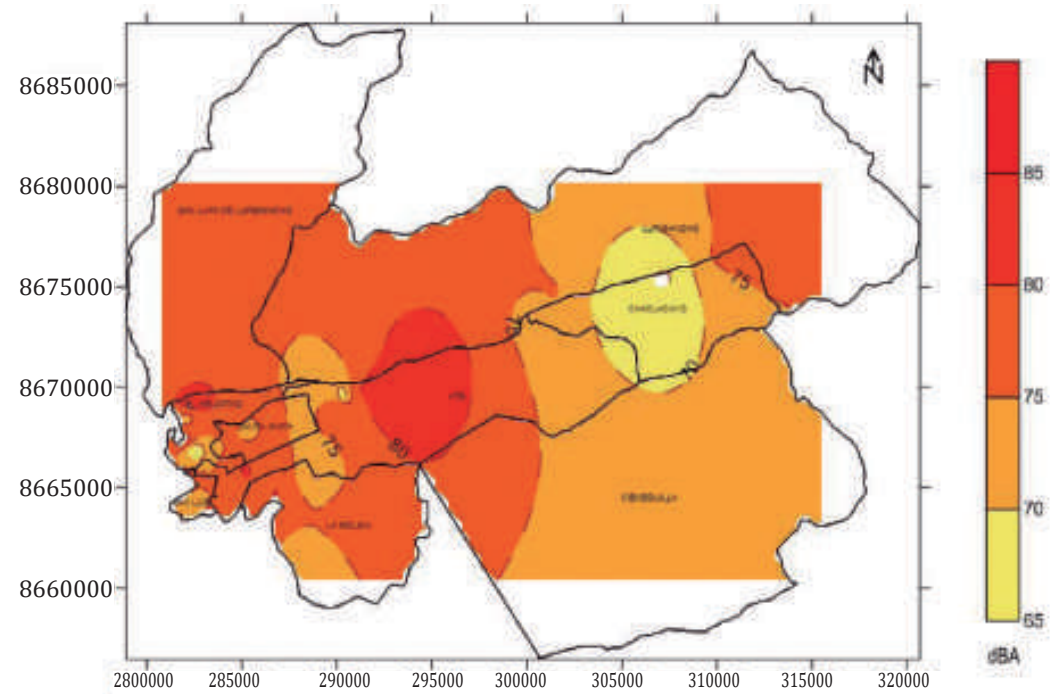

Fuente: Extraído de OEFA (2016: 40). 
COMPARACIÓN DE LOS NIVELES DE RUIDO, NORMATIVA Y GESTIÓN DE RUIDO AMBIENTAL EN LIMA Y CALlaO RESPECTO A OTRAS CIUdAdES DE LATINOAMÉRICA / HÉCTOR GUILlERMo GAMERo MotTA

Figura 5.

Mapa de isófonas de Lima Norte



Fuente: Extraído de OEFA (2016: 41).

Figura 6.

Mapa de isófonas de Lima Sur



Fuente: Extraído de OEFA (2016: 42). 


\subsection{Callao}

El Callao cuenta con una extensión de $148,5 \mathrm{~km}^{2}$ y en ese entonces la población superaba los 800 mil habitantes (valores obtenidos de la Municipalidad del Callao y el censo realizado por el INEI en 2007, respectivamente).

En la provincia del Callao, de los 26 puntos medidos, solo 19 se podían catalogar dentro de una zona de aplicación, siendo solo 1 punto evaluado el que no excede los ECA del ruido. La figura 7 indica los puntos a medir.

Figura 7.

Cantidad de puntos de medición por tipo de zona de aplicación que exceden los ECA de ruido en Callao



Zonas de aplicación

Fuente: Extraído de OEFA (2016: 49).

A continuación, se muestran los 10 puntos más críticos de la provincia en la tabla 7 y el mapa de isófonas en la figura 8. 
COMPARACIÓN DE LOS NIVELES DE RUIDO, NORMATIVA Y GESTIÓN DE RUIDO AMBIENTAL EN LIMA Y CALlaO RESPECTO A OTRAS CIUDADES DE LATINOAMÉRICA / HÉCTOR GUILlERMo GAMERo MotTA

Tabla 7.

Resultados de los 10 puntos de mayor nivel de presión sonora en el Callao

\begin{tabular}{|c|c|c|c|c|c|c|}
\hline \multirow{2}{*}{$\mathbf{N}$} & \multirow{2}{*}{ Distrito } & \multicolumn{2}{|c|}{ Punto de medición } & \multirow{2}{*}{ Descripción } & \multirow{2}{*}{$\begin{array}{c}\text { Zona de } \\
\text { aplicación }\end{array}$} & \multirow{2}{*}{$\begin{array}{c}\text { LAEQ,T } \\
\text { (dBA) }\end{array}$} \\
\hline & & Cod. RENIEC & Cod. OEFA & & & \\
\hline 1 & Bellavista & 240102-RUI-03 & 680,RUI-03 & $\begin{array}{l}\text { Av.Santa } \\
\text { Rosa con } \\
\text { Av. Oscar } \\
\text { Benavides }\end{array}$ & Comercial & 86,3 \\
\hline 2 & Ventanilla & 240106-RUI-01 & 683,RUI-01 & $\begin{array}{l}\text { Av. Néstor } \\
\text { Gambeta } \\
\text { (Alt. } \\
\text { Policlínico } \\
\text { Enmanuel) }\end{array}$ & $\begin{array}{l}\text { Protección } \\
\text { Especial }\end{array}$ & 81,1 \\
\hline 3 & Callao & 240101-RUI-04 & 682,RUI-04 & $\begin{array}{l}\text { Av. Faucett } \\
\text { con Av. } \\
\text { Canta }\end{array}$ & Comercial & 80,3 \\
\hline 4 & $\begin{array}{c}\text { Carmen de } \\
\text { la Legua } \\
\text { Reynoso }\end{array}$ & 240104-RUI-04 & 681,RUI-04 & $\begin{array}{l}\text { Av. Elmer } \\
\text { Faucett } \\
\text { (Hospital } \\
\text { San José) }\end{array}$ & Comercial & 79,4 \\
\hline 5 & Callao & 240101-RUI-01 & 682,RUI-01 & $\begin{array}{l}\text { Av. Néstor } \\
\text { Gambeta } \\
\text { con Av. Los } \\
\text { Ferroles }\end{array}$ & Otros usos & 79,4 \\
\hline 6 & Bellavista & 240102-RUI-01 & 680,RUI-01 & $\begin{array}{l}\text { Av. } \\
\text { Venezuela } \\
\text { con Av. } \\
\text { Faucett }\end{array}$ & Otros usos & 79,2 \\
\hline 7 & Callao & 240101-RUI-03 & 682,RUI-03 & $\begin{array}{l}\text { Óvalo } \\
\text { Cantolao } \\
\text { (cerca a Av. } \\
\text { Gambeta) }\end{array}$ & Otros usos & 78,7 \\
\hline 8 & Ventanilla & 240106-RUI-03 & 683,RUI-03 & $\begin{array}{l}\text { Av. Néstor } \\
\text { Gambeta } \\
\text { (Refinería } \\
\text { La Pampilla) }\end{array}$ & Industrial & 78,7 \\
\hline 9 & $\begin{array}{c}\text { Carmen de } \\
\text { la Legua } \\
\text { Reynoso }\end{array}$ & 240104-RUI-01 & 681,RUI-01 & $\begin{array}{l}\text { Av. Faucett } \\
\text { con Av. } \\
\text { Morales } \\
\text { Duarez) }\end{array}$ & Comercial & 78,3 \\
\hline 10 & Ventanilla & 240106-RUI-05 & 683,RUI-05 & $\begin{array}{l}\text { Av. Júpiter } \\
\text { con Av. La } \\
\text { Playa }\end{array}$ & Comercial & 77,2 \\
\hline
\end{tabular}

Fuente: Extraído de OEFA (2016: 51). [falta transcribir] 
Figura 8.

Mapa de Isófonas en el Callao

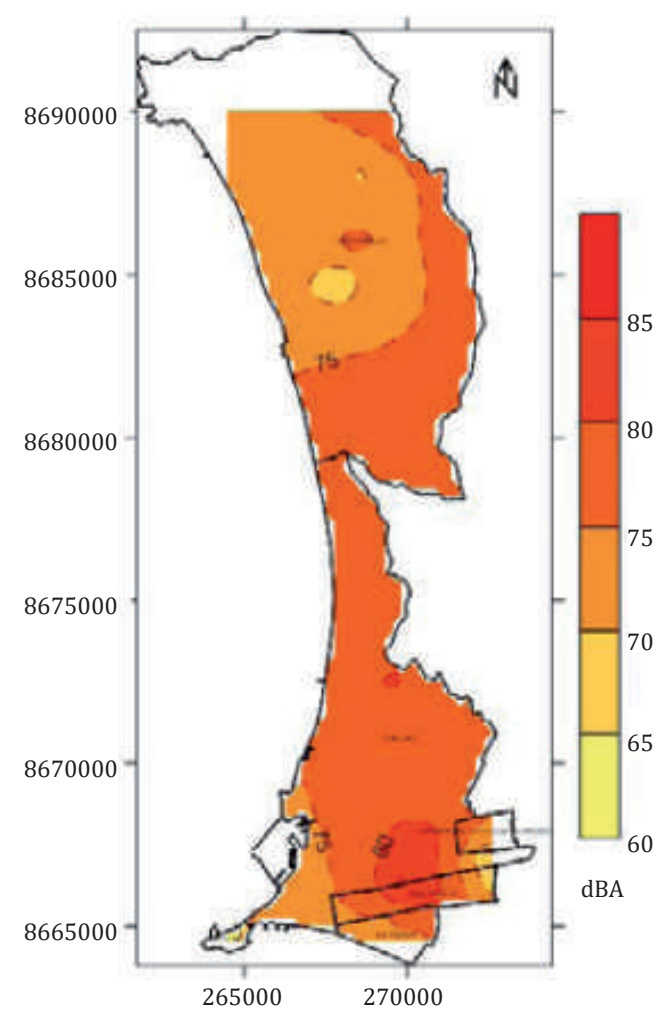

Fuente: Extraído de OEFA (2016: 50).

De ambos registros se concluye que el principal causante del ruido es el tráfico vehicular (ya sea por el ruido del motor, las bocinas, etcétera). Además, las zonas son, en su mayoría, comerciales, lo cual explica la concentración de transporte público, vehículos menores (mototaxis) y el consecuente exceso de gente que genera ruido. El impacto que sufre la población ante este tipo de contaminación es el detrimento de su salud a distintas escalas, con lo que se puede decir que en Lima y Callao las personas padecen molestia constante por el ruido que en el día genera déficit cognoscitivo en centros laborales y de estudio, y en la noche deriva en trastornos del sueño, afectando el bienestar de las personas. Sin embargo, mayor preocupación genera que las personas expuestas todo el día a ese ruido constante (como trabajadores en mercados, policías de tránsito, transportistas, entre otros) están desarrollando la pérdida gradual de la audición sin que lo noten, según lo indicado por la EPA y la OMS en la tabla 2. 
COMPARACIÓN DE LOS NIVELES DE RUIDO, NORMATIVA Y GESTIÓN DE RUIDO AMBIENTAL EN LIMA Y CALlaO RESPECTO A OTRAS CIUdAdES DE LATINOAMÉRICA / HÉCTOR GUILlERMo GAMERo MotTA

Sumado a este informe, la asociación Lima Cómo Vamos (2019) realizó encuestas de percepción de las personas de Lima y Callao ante el ruido. El informe indica que en el año en que se emitió el reporte de la OEFA (2016), el 52,2\% de encuestados en Lima se encontraba insatisfecho con el control de niveles de ruido en las calles, mientras que en Callao fue de 52\%. Más críticos aún fueron los resultados de 2019, donde la insatisfacción al control de niveles de ruido en las calles de Lima fue de 66,5\%, y en Callao fue de $70,8 \%$.

Según esta información recopilada, se verifica la premisa de que Lima y Callao tienen un serio problema de contaminación acústica. Asimismo, es importante agregar que a finales del año 2019 la Municipalidad de Lima realizó un mapa de ruido a partir de mediciones en 33 puntos del Cercado de Lima que confirman la situación de contaminación sonora. En base a este reciente estudio se buscó encontrar medidas para el control del ruido y también de su estudio, es por ello que se realizaron talleres de elaboración de mapas de ruido para varias municipalidades en Lima Metropolitana. Sin embargo, a pesar de que se realizan campañas de medición del ruido y encuestas para conocer la percepción de las personas ante este fenómeno, resulta intrigante saber por qué el ruido continúa siendo un contaminante que no ha logrado ser controlado, ni en Lima ni en Callao, como debiese.

Para ello se recopilará toda la normativa que rige al Estado peruano en cuanto a la acústica ambiental.

\section{Marco legal / normativa y gestión de ruido ambiental en Perú, Chile y Colombia}

\subsection{Perú}

En 2001 se dio la ley 27446, Ley del Sistema Nacional de Evaluación de Impacto Ambiental, la cual se reglamentó mediante un decreto supremo en 2009. Esta tuvo como fin informar que el ruido posee un impacto ambiental en las etapas de cualquier proyecto y que deben mitigarse sus efectos. Para ello se crea el Sistema Nacional de Evaluación del Impacto Ambiental (SEIA).

En 2003 se emitió el decreto supremo que establece el Reglamento de los Estándares Nacionales de Calidad Ambiental para el Ruido, en donde principalmente se busca no exceder límites permitidos de ruido, instituyendo los ECA de ruido a fin de proteger la salud y mejorar la calidad de vida de las personas. Para ello establece que tanto las municipalidades provinciales como las distritales deben monitorear la contaminación sonora y fiscalizar en caso se incumpla con el reglamento. 
Dos años después, en 2005, se publica la Ley General del Ambiente, ley 28611, donde se establecen parámetros de evaluación de ruido.

En 2007, Indecopi dicta normas NTP-ISO, que conforman un Protocolo Nacional de Monitoreo de Ruido Ambiental, parte 1 (2007) y parte 2 (2008), en donde se detallan conceptos y procedimientos de medida para determinar las presiones de ruido.

En 2008 se crea el Ministerio del Ambiente (MINAM), lo cual supuso promover la gestión ambiental y el aprovechamiento sostenible de los recursos naturales. Desde el ámbito de la acústica ambiental, se dirigen el Sistema Nacional de Gestión Ambiental (SNGA) y el Sistema Nacional de Evaluación del Impacto Ambiental (SEIA).

Luego se crea el Organismo de Evaluación y Fiscalización Ambiental (OEFA), en 2008, una entidad perteneciente al MINAM, que promueve la mejora del Sistema Nacional de Gestión Ambiental (SNGA) y es el ente rector del Sistema Nacional de Evaluación y Fiscalización Ambiental (SINEFA) y de Entidades de Fiscalización Ambiental (EFA).

Luego de esto, en 2009 se dio la ley del Sistema Nacional de Evaluación y Fiscalización Ambiental, en donde se indica que las autoridades que forman parte del Sistema de Evaluación y Fiscalización Ambiental son la OEFA, el MINAM y las entidades regionales y locales.

En 2013 se dispuso de un Régimen Común de la Fiscalización Ambiental, donde se busca que las EFA cumplan con sus funciones de manera homogénea e integrada. También en ese año se aprobó, mediante un decreto supremo, el Protocolo Nacional de Monitoreo de Ruido Ambiental, en donde se establecen metodologías y procedimientos a considerar para monitoreos de ruido ambiental por todo ente público o privado que desee hacer dicha evaluación.

En 2016, la Dirección General de Calidad Ambiental del MINAM elaboró los Lineamientos para la Elaboración de Planes de Acción para la Prevención y Control de la Contaminación Sonora. En este documento se busca dar pautas generales para que, en un trabajo en conjunto entre autoridades municipales y empresas, puedan elaborar planes de acción contra la contaminación sonora.

En el año 2019, a través de un decreto supremo, se establecieron los Límites Máximos Permisibles de ruido generado por aeronaves que operan en territorio peruano, con el fin de salvaguardar un ambiente tranquilo y adecuado para las personas.

En el ámbito privado, el Perú es miembro fundador de la Federación Iberoamericana de Acústica (FIA), que actualmente tiene su sede presidencial en Buenos Aires y la vicepresidencia en Lima. A su vez, en el país existe una Sociedad Peruana de Acústica. Cabe resaltar que el Perú no cuenta con una carrera universitaria de acústica, solo a nivel técnico se ven temas de audio, 
COMPARACIÓN DE LOS NIVELES DE RUIDO, NORMATIVA Y GESTIÓN DE RUIDO AMBIENTAL EN LIMA Y CALlAo RESPECTO A OTRAS CIUdAdES De LATINOAMÉRICA / HÉCTOR GUILLERMo GAMERo MotTA

en general, y en las carreras de ingeniería ambiental y arquitectura se tocan tan solo temas necesarios de acústica ambiental y acústica arquitectónica, respectivamente.

Ahora se buscará conocer la situación de países vecinos en la región para compararla con la realidad nacional y analizar bajo distintas perspectivas el trasfondo del problema. El caso de Brasil no se estudiará porque, al ser una metrópoli más grande, con mayor población y movimiento comercial, posee un panorama más complejo respecto a problemas del tráfico (aéreo y vehicular) y por ende del ruido, lo que hace que la comparación no sea tan aplicable.

\subsection{Chile}

Chile alcanzó una población de 18,5 millones de habitantes en 2017 (Grupo Banco Mundial 2020). Su capital Santiago o Gran Santiago tiene una extensión de $641 \mathrm{~km}^{2}$ y una población de más de 6,1 millones de habitantes (Corporación Ciudades 2019)

El parque automotor chileno ascendió a más de 2,15 millones de vehículos y en 2025 será de 2,7 millones, indicó el Instituto Nacional de Estadística (INE) en 2018.

En el caso de Chile, según un reporte sobre la gestión de control de ruido del Ministerio del Ambiente (2010-2014), solo se tenían registros de ruido mayoritariamente en Santiago que datan de 1989. Luego, con el pasar de los años, se realizaron encuestas en distintas regiones, como Valdivia o Iquique, donde se señala que las principales fuentes de ruido son el tráfico vehicular y las fiestas particulares.

En el marco normativo, en 1994 se creó la Comisión Nacional del Medio Ambiente (CONAMA), la cual le dio una mirada integral al problema del ruido, abarcando temas de educación y fiscalización ambiental en instancias como el Servicio de Salud Metropolitano del Ambiente, la Sociedad Chilena de Acústica, universidades, entre otros.

Otra normativa importante del Gobierno fue el Decreto SupremoNorma de Emisión de Ruidos Molestos Generados por Fuentes Fijas en 1998, el cual regulaba el impacto acústico y fiscalizaba la norma, no solo en proyectos públicos, sino también en privados. De este modo, el número de consultoras acústicas aumentó considerablemente debido a que se analizaba el impacto ambiental que tenía el ruido en estos proyectos. En este decreto se delimitan, además, los límites máximos de presión sonora corregidos (NPC) para la ciudad. Vale decir que en 2011 se hizo una modificación de los valores de horario nocturno, por lo que en la tabla 8 se muestran los valores vigentes. 
Tabla 8.

Niveles máximos permisibles de presión sonora corregidos en Chile

\begin{tabular}{l|c|c|}
\multirow{2}{*}{ Zonas } & Horario diurno (7-21 horas) & Horario nocturno (21-7 horas) \\
\cline { 2 - 3 } & \multicolumn{2}{|c|}{ Valores expresados en dB(A) } \\
\hline Zona I & 55 & 45 \\
\hline Zona II & 60 & 50 \\
\hline Zona III & 65 & 50 \\
\hline Zona IV & 70 & 70 \\
\hline
\end{tabular}

Fuente: Extraído de MMA Chile (2011: 51).

La zona I es de uso residencial, la zona II corresponde a equipamiento a escala regional, la zona III permite actividades productivas y de infraestructura y la zona IV actividades productivas y de infraestructura, pero de carácter más nocivo.

En el lado académico, Chile cuenta con la Sociedad Chilena de Acústica (SOCHA) y a su vez es miembro fundador de la Federación Iberoamericana de Acústica (FIA). Además, Chile dispone de varias universidades donde se estudia la carrera de ingeniería de sonido e ingeniería acústica, como por ejemplo la Universidad Austral de Chile, la cual fue fundada por el decreto supremo N3.757 en 1954.

Posteriormente, se dictaron una serie de normas y decretos, y se tomaron importantes iniciativas, las cuales se muestran a continuación:

- $\quad$ Decreto supremo N129/02 del Ministerio de Transporte - Norma de Emisión de Ruido para Buses de Locomoción Colectiva Urbana y Rural que regula el ruido de buses al ingresar al parque automotor (2003).

- $\quad$ Norma Chilena Oficial NCh352/1.0f2000 Aislación Acústica - Parte 1: Construcciones de Uso Habitacional - Requisitos mínimos y ensayos, que establece las condiciones acústicas en construcciones de uso habitacional.

- $\quad$ Realización anual del Seminario de Contaminación Acústica y Control de Ruido Ambiental, desde 1995.

- Campaña de sensibilización del Ruido: «Baja el Volumen», desde 2009.

- Norma de Emisión de Ruidos Generados por Actividades de Construcción (en proceso).

- Norma de Emisión de Ruido para Vehículos Livianos, Medianos y Motocicletas (2019).

- Creación de la plataforma MapCity life, que nació de la iniciativa de gestión de ruido del Ministerio del Ambiente de 2008, en donde se pueden ver los niveles de ruido de ciudades como Santiago y Valdivia, entre otras, con solo mover el cursor sobre el mapa. 
COMPARACIÓN DE LOS NIVELES DE RUIDO, NORMATIVA Y GESTIÓN DE RUIDO AMBIENTAL EN LIMA Y CALlaO RESPECTO A OTRAS CIUdAdES DE LATINOAMÉRICA / HÉCTOR GUILlERMo GAMERo MotTA

Sin embargo, la gestión presenta problemas en relación al aislamiento acústico de edificaciones, ya que no se protege la calidad de vida de la población. En cuestión de fiscalización, por ejemplo, hay muchas denuncias por fiestas particulares y no es posible atenderlas todas. También hay problemas en el ordenamiento territorial, ya que se generan conflictos debido a la incompatibilidad de actividades que producen ruido en una zona específica.

Cabe resaltar que por mucho tiempo hubo una falta grande de información cuantificada acerca del ruido ambiental, el cual fue subsanado al realizar mapas de ruido desde el año 2007 y permitió focalizar los problemas para buscarles una solución óptima. A la fecha, se tienen mapas de Antofagasta, Providencia y Santiago.

\section{- Estrategia para la Gestión del Control de Ruido Ambiental (2010-2014)}

Chile cuenta con un plan a futuro que se basa en tres ejes: educación, fiscalización e información, con el cual se busca que la población de centros urbanos de más de 50 mil habitantes esté expuesta a adecuados niveles de ruido.

\section{Figura 9.}

\section{Pilares de la gestión del control de ruido en Chile}

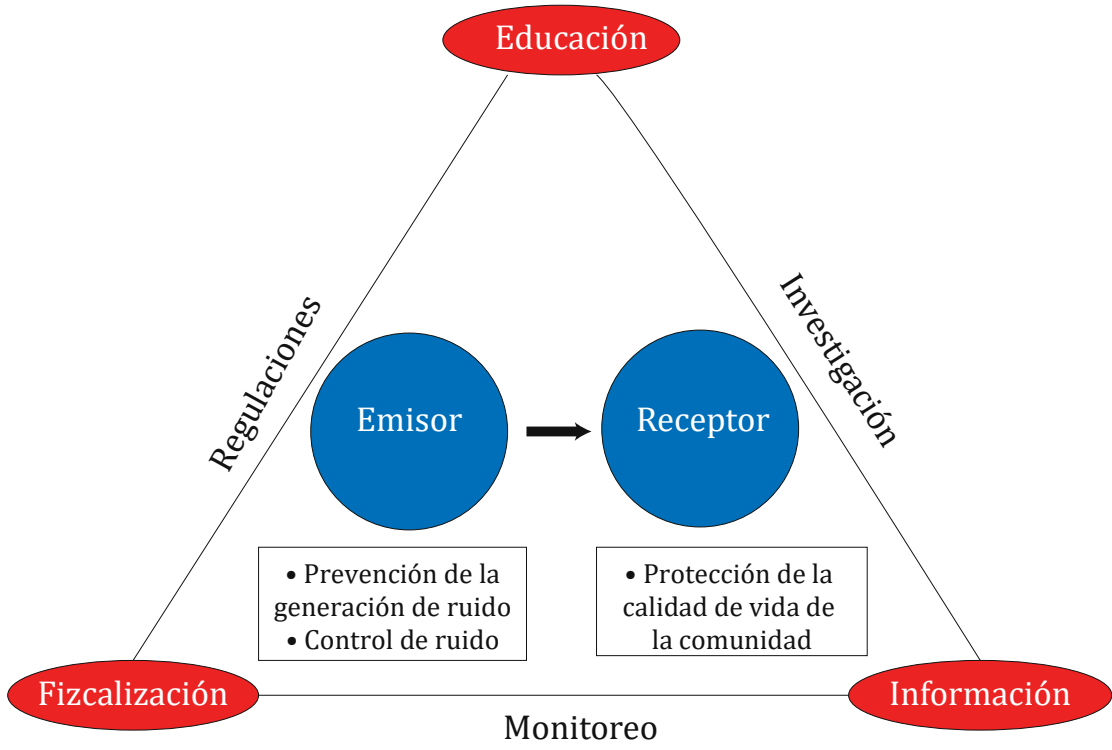

Fuente: Extraído de MMA Chile (2014: 9). 
Para un mayor análisis se recomienda leer la estrategia completa del reporte del Ministerio del Medio Ambiente.

\section{- Mapa de ruido del Gran Santiago}

El mapa de ruido de la Gran Santiago fue elaborado por la Universidad Austral de Chile a pedido del Ministerio del Medio Ambiente (MMA) y se hizo mediante un software para modelar los niveles de presión sonora continuo equivalente con ponderación A (LAeq,T), el cual indica un valor fijo de sonoridad en un intervalo de medición y funciona como un promedio del nivel de presión sonora en los puntos evaluados. De este modo, se cuentan con registros de toda la ciudad. El procedimiento para este mapa de ruido inició recolectando información de valores medidos en campañas anteriores de niveles de presión sonora continuo equivalente con ponderación A (LAeq,T), haciendo uso de sonómetros en periodos de 15 minutos en horas valle y pico, tanto en horario diurno como nocturno. Luego se recabó información de las diferentes vías urbanas, su tipología, cartografía y posterior segmentación de calles, para luego hacer el modelado en relación al ruido provocado por el tránsito vehicular. A continuación, se muestran los mapas de ruido (Figuras 10 y 11).

El mapa de ruido de Santiago de Chile en horario diurno muestra tonos de color azul opaco en el centro de Santiago, de 75 a 80 dB(A). En los alrededores es un tono naranja oscuro, por lo que la presión sonora está entre 50 y $60 \mathrm{~dB}(\mathrm{~A})$. Cabe resaltar que estos valores son de vecindarios o zonas de comercio y solo en vías de gran envergadura donde el flujo vehicular es muy alto los niveles ascienden a más de $80 \mathrm{~dB}$. Otro punto clave es que en las periferias de la ciudad los valores bajan dramáticamente a 30 o $45 \mathrm{~dB}$. En el centro (plaza de armas) los valores varían entre 60 y $75 \mathrm{~dB}(\mathrm{~A})$. De esto, el informe de la elaboración del mapa de ruido de la Gran Santiago concluye que un 17,35\% de la ciudad se encuentra por encima de los $65 \mathrm{~dB}(\mathrm{~A})$.

En horario nocturno los valores bajan y en general el ruido es de 55 $\mathrm{dB}(\mathrm{A})$ en promedio. 
COMPARACIÓN DE LOS NIVELES DE RUIDO, NORMATIVA Y GESTIÓN DE RUIDO AMBIENTAL EN LIMA Y CALLAO RESPECTO A OTRAS CIUDADES DE LATINOAMÉRICA / HÉCTOR GUILLERMO GAMERO MOTTA

Figura 10.

Mapa de ruido del Gran Santiago Urbano-Horario diurno

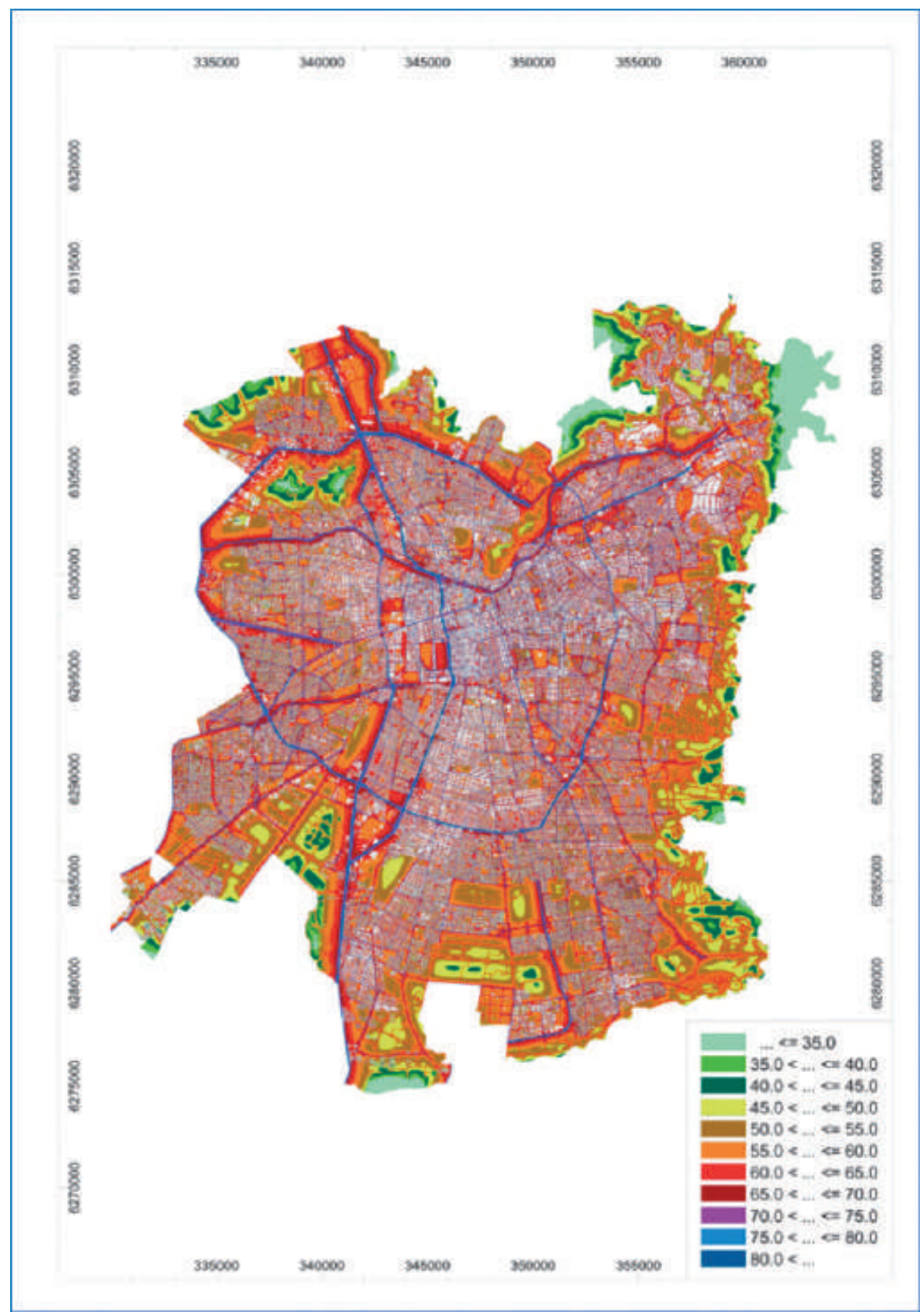

Fuente: Extraído de MMA Chile (2016: s/p). 
REVISTA KAWSAYPACHA: SOCIEDAD Y MEDIO AMBIENTE N 5 (2020)

Figura 11.

Mapa de ruido del Gran Santiago Urbano-Horario nocturno

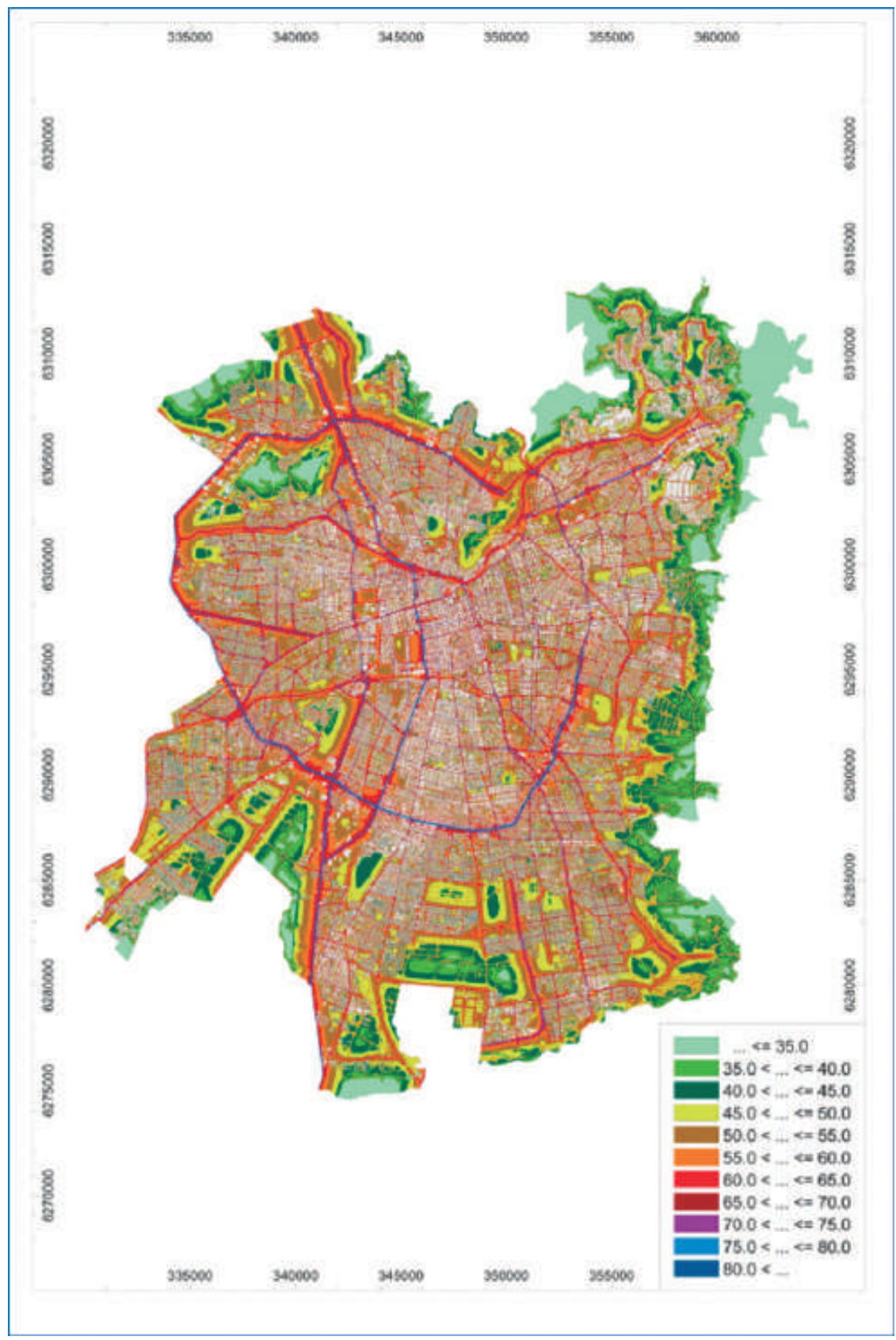


COMPARACIÓN DE LOS NIVELES DE RUIDO, NORMATIVA Y GESTIÓN DE RUIDO AMBIENTAL EN LIMA Y CALlaO RESPECTO A OTRAS CIUdAdES DE LATINOAMÉRICA / HÉCTOR GUILlERMo GAMERo MotTA

\subsection{Colombia}

Colombia tiene una población de 48,2 millones de habitantes (Dane 2019). Su capital Bogotá tiene una extensión de $1.775 \mathrm{~km}^{2}$ y una población de más de 7,4 millones de habitantes (Dane 2019).

El parque automotor de la capital ascendió a 2,4 millones de vehículos y al 2025 será de más de 3 millones (Bogotá Cómo Vamos 2019).

En el caso colombiano, la información obtenida del trabajo Revisión de la normatividad para el ruido acústico en Colombia y su aplicación, elaborado por Casas, Betancur y Montaño en 2015, permite conocer el dictamen de normas que regulan las fuentes de ruido, el cual se inició con la creación del Instituto Nacional de Recursos Naturales en 1968. De este modo se empezó a concientizar a la población sobre el ruido y debido a que se hicieron notorios los problemas en 1983, el Ministerio de Salud estipuló la resolución 8321 para dictar medidas de protección a la audición de las personas. Una de estas fue determinar periodos para definir valores permitidos de ruido, siendo el horario diurno desde las 07:01 horas hasta las 21:00, mientras que el horario nocturno desde las 22:01 horas hasta las 07:00 horas del día siguiente. Luego, en 1992, con una Conferencia de las Naciones Unidas, se fijan acuerdos de sostenibilidad ambiental. Así, en 1995, luego de creado el Ministerio del Medio Ambiente, se promulgó el decreto 948 que reglamenta las leyes que anteriormente se habían hecho y sanciona con multas cuando se viola lo impuesto por la resolución 8321.

Luego, en 2006 se promulgó la resolución 0627, donde se da la norma de emisión de ruido ambiental y se buscó salvaguardar la salud de las personas al determinar estándares de ruido por sectores. La tabla 9 señala los valores máximos permisibles.

En el ámbito privado, Colombia cuenta con la Asociación Colombiana de Acústica y es miembro de la FIA. También se enseña la carrera de ingeniería de sonido en institutos y en la Universidad de San Buenaventura, que implementó su carrera profesional en el año 2000.

Una serie de mediciones se hicieron en Bogotá, Medellín, etcétera. Solo para mencionar el caso de la capital colombiana, se obtuvo que la zona más contaminada tenía varios puntos que fluctuaban entre 75 y $95 \mathrm{~dB}(\mathrm{~A})$. 
Tabla 9.

Estándares máximos permisibles de niveles de ruido en Colombia

\begin{tabular}{|c|c|c|c|c|c|}
\hline \multirow[t]{2}{*}{ Sector } & \multirow[t]{2}{*}{ Subsector } & \multicolumn{2}{|c|}{$\begin{array}{c}\text { Estándares } \\
\text { máximos } \\
\text { permisibles de } \\
\text { niveles de emisión } \\
\text { de ruido (dBA) }\end{array}$} & \multicolumn{2}{|c|}{$\begin{array}{c}\text { Estándares } \\
\text { máximos } \\
\text { permisibles de } \\
\text { niveles de ruido } \\
\text { ambiental (dBA) }\end{array}$} \\
\hline & & Día & Noche & Día & Noche \\
\hline $\begin{array}{l}\text { Sector A: } \\
\text { Tranquilidad y } \\
\text { silencio }\end{array}$ & $\begin{array}{l}\text { Hospitales, biblioteca, } \\
\text { guarderías, sanatorios, } \\
\text { hogares geriátricos }\end{array}$ & 55 & 50 & 55 & 45 \\
\hline \multirow{3}{*}{$\begin{array}{l}\text { Sector B: } \\
\text { Tranquilidad y } \\
\text { ruido moderado }\end{array}$} & $\begin{array}{l}\text { Zonas residenciales o } \\
\text { exclusivamente diseñadas } \\
\text { para desarrollo habitacional, } \\
\text { hotelería y hospedaje }\end{array}$ & \multirow{3}{*}{65} & \multirow{3}{*}{55} & \multirow{3}{*}{65} & \multirow{3}{*}{50} \\
\hline & $\begin{array}{l}\text { Universidades, colegios, } \\
\text { escuelas, centros de estudio e } \\
\text { investigación }\end{array}$ & & & & \\
\hline & $\begin{array}{l}\text { Parques en zonas urbanas } \\
\text { diferentes a los parques } \\
\text { mecánicos al aire libre }\end{array}$ & & & & \\
\hline \multirow{5}{*}{$\begin{array}{l}\text { Sector C: Ruido } \\
\text { intermedio } \\
\text { restringido }\end{array}$} & $\begin{array}{l}\text { Zonas con usos permitidos } \\
\text { industriales, como industrias } \\
\text { en general, zonas portuarias, } \\
\text { parques industriales, zonas } \\
\text { francas }\end{array}$ & 75 & 75 & 75 & 70 \\
\hline & $\begin{array}{l}\text { Zonas con usos permitidos } \\
\text { comerciales, como centros } \\
\text { comerciales, almacenes, } \\
\text { locales o instalaciones de tipo } \\
\text { comercial, talleres de mecánica } \\
\text { automotriz e industrial, centros } \\
\text { deportivos y recreativos, } \\
\text { gimnasios, restaurantes, bares, } \\
\text { tabernas, discotecas, bingos, } \\
\text { casinos }\end{array}$ & 70 & 60 & 70 & 55 \\
\hline & $\begin{array}{l}\text { Zonas con uso permitidos de } \\
\text { oficinas }\end{array}$ & \multirow[t]{2}{*}{65} & \multirow[t]{2}{*}{55} & \multirow[t]{2}{*}{65} & \multirow[t]{2}{*}{50} \\
\hline & Zonas con usos institucionales & & & & \\
\hline & $\begin{array}{l}\text { Zonas con otros usos } \\
\text { relacionados, como parques } \\
\text { mecánicos al aire libre, áreas } \\
\text { destinadas a espectáculos } \\
\text { públicos al aire libre }\end{array}$ & 80 & 75 & 80 & 70 \\
\hline \multirow{3}{*}{$\begin{array}{l}\text { Sector D: Zona } \\
\text { suburbana o rural } \\
\text { de tranquilidad y } \\
\text { ruido moderado }\end{array}$} & Residencial suburbana & \multirow[b]{3}{*}{55} & \multirow[b]{3}{*}{50} & \multirow[b]{3}{*}{55} & \multirow[b]{3}{*}{45} \\
\hline & $\begin{array}{l}\text { Rural habitada destinada a } \\
\text { explotación agropecuaria }\end{array}$ & & & & \\
\hline & $\begin{array}{l}\text { Zonas de recreación y descanso, } \\
\text { como parques naturales y } \\
\text { reservas naturales }\end{array}$ & & & & \\
\hline
\end{tabular}


COMPARACIÓN DE LOS NIVELES DE RUIDO, NORMATIVA Y GESTIÓN DE RUIDO AMBIENTAL EN LIMA Y CALlaO RESPECTO A OTRAS CIUdAdES DE LATINOAMÉRICA / HÉCTOR GUILlERMo GAMERo MotTA

\section{- Mapa de ruido de Bogotá}

Según el mismo estudio revisado, el mapa de ruido de Bogotá se hizo dividiendo en sectores en función al tipo de uso (comercial, vivienda, zona de protección especial, etcétera), midiendo niveles de presión sonora continuo equivalente con ponderación A (LAeq,T) con un sonómetro en periodos de 8 horas y valores máximos en dicho periodo, además de relacionar el tráfico circulante en cada zona. A continuación, se muestran los mapas de ruido:

Figura 12.

\section{Mapa de ruido de Bogotá-Horario diurno}

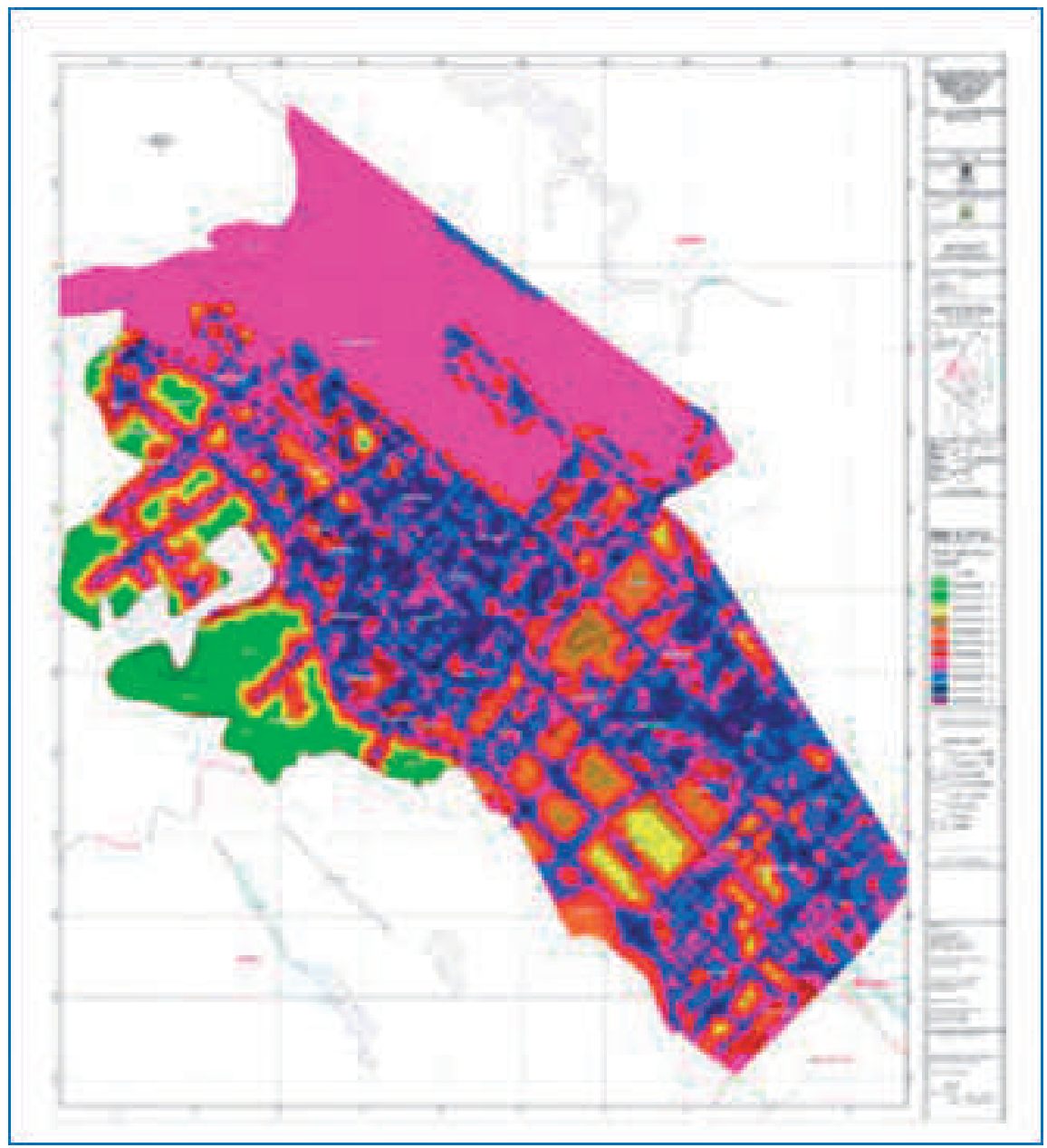

Fuente: Extraído de Casas, Betancur y Montaño (2015: 274). 
Figura 13.

Mapa de ruido de Bogotá-Horario nocturno

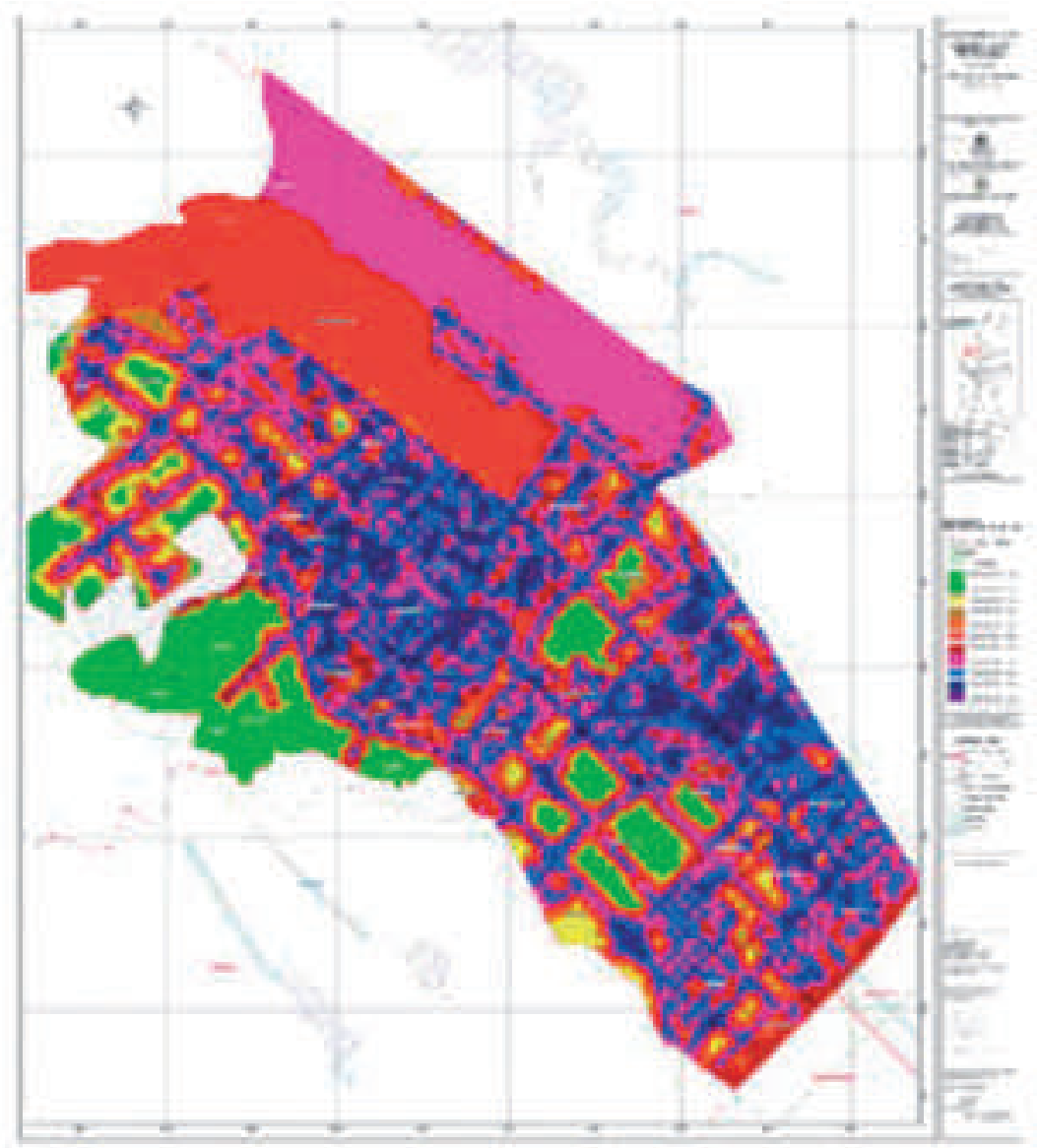

Fuente: Extraído de Casas, Betancur y Montaño (2015: 274).

De esta manera se obtuvo que en horario diurno se muestran, en su mayoría, tonalidades de azul y rojo, por lo que, en general, el ruido fluctuaba entre los 60 y $80 \mathrm{~dB}(\mathrm{~A})$, y que en algunos puntos críticos el ruido llegaba hasta valores de $95 \mathrm{~dB}(\mathrm{~A})$. En horario nocturno variaron poco los niveles, ya que en su mayoría igual se sobrepasaban los $80 \mathrm{~dB}(\mathrm{~A})$. El estudio concluye que los niveles de ruido se deben principalmente al tráfico vehicular, actividades comerciales o al sector construcción. 
COMPARACIÓN DE LOS NIVELES DE RUIDO, NORMATIVA Y GESTIÓN DE RUIDO AMBIENTAL EN LIMA Y CALlAo RESPECTO A OTRAS CIUDAdES DE LATINOAMÉRICA / HÉCTOR GUILLERMO GAMERo MotTA

\section{Comparación entre los países}

\subsection{Comparación de la normativa de los países}

La base para comparar los niveles de ruido entre las ciudades es conocer los niveles permitidos de ruido según la normativa del país. Es por eso que en la tabla 10 se muestran los límites máximos permisibles del ruido en horario diurno y nocturno para cada país.

Tabla 10.

Valores límite máximos de ruido en Perú, Colombia y Chile

\begin{tabular}{|l|c|c|c|c|c|c|}
\hline \multirow{2}{*}{} & \multicolumn{2}{|c|}{ Perú } & \multicolumn{2}{c|}{ Colombia } & \multicolumn{2}{c|}{ Chile } \\
\cline { 2 - 7 } & día & noche & día & noche & día & noche \\
\hline Valor límite máximo $(\mathrm{dBA})$ & 80 & 70 & 80 & 70 & 70 & 70 \\
\hline
\end{tabular}

Fuente: Elaboración propia en base a los niveles máximos permisibles de presión sonora de cada país analizado.

Se observa que los valores, tanto para Perú y Colombia, son los mismos, en cambio Chile tiene menos tolerancia con el ruido industrial en horario diurno, al ser este como máximo de $70 \mathrm{~dB}(\mathrm{~A})$. Vale aclarar que este horario tiene la misma duración en Perú y Colombia (de 7 a 22 horas), pero en Chile se reduce en una hora (de 7 a 21 horas).

Una vez revisados estos estándares, se analizarán las diferencias más resaltantes en cuanto al marco legal. En el caso peruano, si bien existen decretos que establecen los lineamientos acerca de los niveles permisibles de ruido y estipula zonas donde no se pueden exceder a estos niveles, toda la responsabilidad fiscalizadora recae en las municipalidades provinciales y distritales (solo cuando no sea parte de su competencia lo regularán las autoridades ambientales correspondientes). Una vez que ellas establezcan ordenanzas para fiscalizar y gestionar el ruido, recién se puede monitorear la contaminación en el ambiente y sancionar a las personas naturales o jurídicas que infrinjan lo expuesto en la ordenanza.

Resulta importante conocer que ni la mitad de los distritos de Lima Metropolitana cuenta con estas ordenanzas (según lo revisado en el portal del Sistema Nacional de Información Ambiental-SINIA). Es cierto que hay una ordenanza general para Lima Metropolitana y rige a los demás distritos, pero sigue siendo no aplicable en el contexto real.

Lo que es aún más crítico es que los municipios que sí poseen normas de prevención, gestión y fiscalización no cumplen lo que indica su ordenanza, dando como resultado que a pesar de tener leyes, normas e incluso reglamentos no se regule el ruido en la capital. 
Otro punto es que en el país recién se tomó conciencia del ruido como contaminante a partir del Reglamento 2003, en cambio, en países como Chile y Colombia estas normas datan de la década de los noventa, así como sus organismos de protección del ambiente, que en el caso peruano recién se crearon en 2008. Además, en el país no se realizan campañas de protección contra el ruido en la magnitud que deberían ni con la frecuencia adecuada, tampoco se concientiza en los colegios acerca de los problemas de salud que trae la contaminación acústica, a diferencia de Chile donde es muy difundido el Día Contra el Ruido o las campañas para bajar el ruido en las calles, que son más aceptadas por la sociedad y han generado en ella un sentido de que el ruido también afecta al confort urbano.

Incluso el no tener un plan de gestión de ruido ambiental, como lo tiene Chile, hace que las normas en el Perú no se cumplan, que las mediciones no representen la realidad y que la población siga ignorando las graves consecuencias de este fenómeno ambiental.

\subsection{Comparación entre los mapas de ruido}

Antes de iniciar la comparación, debe tenerse en cuenta que los mapas de ruido analizados, a pesar de ser los más recientes publicados, son de años distintos y es posible que no refleje la situación actual de las ciudades analizadas, pero para fines del estudio permiten un importante análisis.

El principal déficit que muestra el mapa de ruido de Lima y Callao es que solo presenta valores de presión sonora en puntos diseminados que buscan representar la realidad del ruido en la capital, pero en verdad no reflejan la situación en la ciudad porque se han medido pocos puntos (de 2 o 12 puntos por distrito) y no se ha modelado estadísticamente para obtener mapas de ruido mucho más precisos como en los países vecinos. Además, al ser mediciones puntuales solo refleja niveles de presión sonora tomados en el momento de la medición, mas no se tiene un modelo que se corresponda mejor a la realidad. También es importante señalar que solo se tiene este registro para Lima y Callao, pero no en otras regiones importantes del país donde el ruido también es un problema, a diferencia de Colombia y Chile que sí tienen mapas de ruido para otras ciudades y no solo para sus capitales.

De comparar los niveles de presión sonora continuo equivalente con ponderación A (LAeq,T) de cada ciudad, se tiene que Santiago posee niveles más bajos tanto en horario diurno como nocturno, ya que sus valores máximos en horario diurno indicados en el mapa de ruido muestran que solo en algunas rutas viales importantes se superan los $80 \mathrm{~dB}(\mathrm{~A})$. Colombia presenta niveles críticos de ruido tanto de día como de noche porque, en general, se superan los $80 \mathrm{~dB}(\mathrm{~A})$ e incluso se llegan a los $95 \mathrm{~dB}(\mathrm{~A})$ en el día. Tales cifras parecen indicar que Bogotá es una ciudad más contaminada 
COMPARACIÓN DE LOS NIVELES DE RUIDO, NORMATIVA Y GESTIÓN DE RUIDO AMBIENTAL EN LIMA Y CALlaO RESPECTO A OTRAS CIUdAdES DE LATINOAMÉRICA / HÉCTOR GUILlERMo GAMERo MotTA

acústicamente que Lima y Callao durante el día, porque el punto más alto en nivel de ruido registrado en el Callao fue de $86.3 \mathrm{~dB}(\mathrm{~A})$. La comparación con el horario de noche no se puede hacer porque la capital peruana no cuenta con esos registros. Por su parte, la OEFA, en su informe sobre la contaminación sonora de Lima y Callao (2016), indica que, del total de puntos medidos en Lima, se superan más del 90\% de los ECA del ruido, y en el Callao su totalidad está por encima de $70 \mathrm{~dB}(\mathrm{~A})$. Por lo que se confirma que la realidad nacional es más similar a la colombiana.

Otro aspecto comparable es que la metodología usada para el mapa de ruido de Lima y Callao solo se basa en mediciones con sonómetro, al igual que en Bogotá (aunque en otras ciudades de Colombia sí se usaron programas estadísticos para conocer qué días son más ruidosos, etcétera). Pero en Chile, como se usaron softwares para modelar los niveles de ruido en base a una gran biblioteca de información de niveles de ruido medidos en épocas anteriores, los mapas de ruido brindan más información.

Es importante señalar que debido a que el principal responsable del ruido es el tráfico rodado, en países como Chile e incluso Colombia se tiene data sobre el tráfico y su relación con niveles de presión sonora para realizar sus mapas de ruido. En el caso de Lima Metropolitana se sabe que para la elección de los puntos se consideró la zonificación según ordenanzas de Lima y se asume que los puntos elegidos fueron seleccionados teniendo conocimiento de flujos vehiculares o zonas que son ruidosas por las actividades que se realizan, pero no se tiene por escrito (o al menos no está disponible a la ciudadanía) qué factores se consideraron para determinar qué puntos medir y qué puntos no. Por ello, es importante hacer énfasis en que la comparación hecha con las demás ciudades se realiza a pesar de desconocer si se usaron los mismos procedimientos y normativa para el registro de puntos de medición, su procesamiento, etcétera.

\subsection{Observaciones finales}

Tabla 11.

Datos comparativos entre ciudades evaluadas

\begin{tabular}{|c|c|c|c|}
\hline Extensión (km2) & Lima & Bogotá & Santiago \\
\hline $\begin{array}{c}\text { Población } \\
\text { (millones de habitantes) }\end{array}$ & 2.800 & 1.775 & 641 \\
\hline $\begin{array}{c}\text { Parque Automotor } \\
\text { (millones de vehículos) }\end{array}$ & 10 & 7,4 & 6,1 \\
\hline
\end{tabular}

Fuente: Elaboración propia en base a la información demográfica, geográfica y de transporte recopilada. 
Comparando dichos factores, se observa que esta tabla comparativa podría dar luces de la situación del ruido en la respectiva ciudad, especialmente en lo referido a su extensión y población. De este modo se desprenden las siguientes observaciones:

- Lima es una ciudad más grande en tamaño y en población, comparada con las otras dos. Sin embargo, el parque automotor sigue siendo mucho menor ya que Santiago, que es cuatro veces más pequeña que Lima y con la mitad de población, tiene un 30\% más de vehículos motorizados.

- $\quad$ Tanto Lima como Bogotá y Santiago tienen tendencia a aumentar la cantidad de vehículos y se prevé que para el 2025 estarán rondando cerca a los 3 millones.

- Diversos estudios sitúan a Bogotá como una de las ciudades más congestionadas del mundo. Incluso, Bogotá se encuentra en el segundo puesto del índice de tráfico mundial de la empresa holandesa de tecnología de navegación TomTom del año 2018, y Lima en el tercero (McCarthy 2019).

\section{Conclusiones}

- Los tres países comparados establecen los límites permisibles de ruido según las recomendaciones de la OMS y EPA, ya que en zonas industriales se restringe el ruido para que no cause pérdida de la audición ni cause mayores estragos contra la salud, y en las demás se busca que el ruido no perturbe la tranquilidad de las personas. Sin embargo, solo Chile cumple esto realmente, puesto que permite niveles máximos de $70 \mathrm{~dB}(\mathrm{~A})$ en el día, mientras que Colombia y Perú permiten $80 \mathrm{~dB}(\mathrm{~A})$.

- Todos los países presentados en el presente trabajo de investigación forman parte de la Federación Iberoamericana de Acústica (FIA) y cada uno posee su asociación según el país, pero se evidencia que solo la de Chile está en actividad, ya que organiza congresos, campañas de concientización contra el ruido, seminarios, etcétera. Es por ello que la población chilena es más consciente del problema y se regula y fiscaliza con mayor efectividad la contaminación acústica, a diferencia de Colombia y Perú.

- Los mapas de ruido, las cifras del parque automotor y el tráfico muestran que Chile tiene un mejor desempeño en la gestión del ruido 
COMPARACIÓN DE LOS NIVELES DE RUIDO, NORMATIVA Y GESTIÓN DE RUIDO AMBIENTAL EN LIMA Y CALlAo RESPECTO A OTRAS CIUdAdES De LATINOAMÉRICA / HÉCTOR GUILLERMo GAMERo MotTA

ambiental en la ciudad que Colombia y Perú, los cuales comparten una realidad muy similar en cuanto a las carencias en gestión y normativa.

- $\quad$ El hecho de no contar con un mapa de ruido sofisticado y de no tener registros de otras ciudades, aparte de la capital, demuestra el poco interés de las autoridades de abordar el problema y el poco alcance de la fiscalización. Esto es símbolo de que no todos los organismos implicados actúan bajo sus distintas competencias para regular la situación y una causa de ello es que no se trabaja en conjunto con profesionales porque, en sí, hay pocos especializados en la acústica en el país, lo que genera un déficit en la gestión que deriva en una mala fiscalización.

- Lima cuenta con una normativa suficiente y que involucra varios organismos que deberían ser capaces de solucionar el problema del ruido, por lo que no se necesitan nuevas normas, sino mejorar las que se tienen y hacer que se cumplan. Para ello se debe tener mayor control, mayores profesionales especializados e invertir más en las entidades que fiscalizan el ruido en las ciudades.

\section{Referencias}

Bogotá Cómo Vamos (2019). «Preocupa crecimiento de parque automotor en Bogotá». https://bogotacomovamos.org/preocupa-crecimiento-deparque-automotor/

Casas, O., Betancur, C., Montaño, J. (2015). Revisión de la normativa para el ruido acústico en Colombia y su aplicación. Entramado, 11(1): 264-286. http:// www.scielo.org.co/pdf/entra/v11n1/v11n1a19.pdf

Corporación Ciudades (2019). Gran Santiago. Región Metropolitana. Corporación Ciudades Chile. http://corporacionciudades.cl/wp-content/ uploads/2019/04/ATLAS-SANTIAGO.pdf

Departamento Administrativo Nacional de Estadística (DANE) (2019). Censo Nacional de Población y Vivienda 2018 Colombia. https://www.dane.gov. co/index.php/estadisticas-por-tema/demografia-y-poblacion/censonacional-de-poblacion-y-vivenda-2018/cuantos-somos

Grupo Banco Mundial (2020). Datos. Banco Mundial: Chile. Banco Mundial https:// datos.bancomundial.org/pais/chile

INEI (2008). Censos Nacionales 2007: XI de Población y Vivienda. Lima, Perú. https:// www.inei.gob.pe/media/MenuRecursivo/publicaciones_digitales/Est/ Lib1136/libro.pdf 
INEI (2014). Una mirada a Lima Metropolitana. Lima, Perú. https://www.inei.gob.pe/ media/MenuRecursivo/publicaciones_digitales/Est/Lib1168/libro.pdf

Lima Cómo Vamos (2016). Evaluando la gestión en Lima 2015. Sexto informe de resultadossobrelacalidad devida.Lima,Perú.http://www.limacomovamos. org/cm/wp-content/uploads/2016/11/InformeGestion2015.pdf

Lima Cómo Vamos (2019). Lima y Callao según sus ciudadanos. Décimo informe urbano de percepción sobre la calidad de vida en la ciudad. Lima, Perú. http://www.limacomovamos.org/wp-content/uploads/2019/11/ Encuesta-2019_web.pdf

McCarthy, N. (5 de junio 2019). The World's Worst Cities For Traffic Congestion [Infographic]. Forbes, business section. https://www.forbes.com/ sites/niallmccarthy/2019/06/05/the-worlds-worst-cities-for-trafficcongestion-infographic/\#5391927b12bc

Ministerio del Ambiente) de la República del Perú (MINAM) (2003). Reglamento de Estándares Nacionales de Calidad Ambiental para Ruido. https://sinia. minam.gob.pe/normas/reglamento-estandares-nacionales-calidadambiental-ruido

Ministerio del Medio Ambiente de Chile (2011). DS 146/97 y DS 38/11. Consideraciones en el SEIA. http://metadatos.mma.gob.cl/sinia/ articles55511_CapacitacionSeremiLaAraucania_25102013.pdf

Moreno, J. (1990). Introducción al control de ruido. Lima, Perú: Bruel and Kjaer.

OEFA (2015). Instrumentos básicos para la fiscalización ambiental. Lima, Perú. https://centroderecursos.cultura.pe/es/registrobibliografico/ instrumentos-b\%C3\%A1 sicos-para-la-fiscalizaci\%C3\%B3n-ambiental

OEFA (2016). La contaminación sonora en Lima y Callao. Lima, Perú. https://www. oefa.gob.pe/?wpfb_dl=19088

OMS (1999). Guías para el ruido urbano. Londres, Reino Unido. https://ocw.unican. es/pluginfile.php/965/course/section/1090/Guias\%2520para\%2520el \%2520ruido\%2520urbano.pdf

OMS (2004). Occupational Noise. https://apps.who.int/iris/bitstream/ handle/10665/43001/9241591927.pdf?sequence=1\&isAllowed=y

Posada, C. (2018). Aumento continuo del parque automotor, un problema que urge solucionar. Cámara de Comercio de Lima. https://www.camaralima. org.pe/repositorioaps/0/0/par/posada_816/posada\%20816_final_ aumento\%20 continuo\%20del\%20parque $\% 20$ automotor.pdf

WHO (2018). Environmental Noise Guidelines for the European Region. Copenhague, Dinamarca. http://www.euro.who.int/en/health-topics/environmentand-health/noise/publications/2018/environmental-noise-guidelinesfor-the-european-region-2018 
COMPARACIÓN DE LOS NIVELES DE RUIDO, NORMATIVA Y GESTIÓN DE RUIDO AMBIENTAL EN LIMA Y CALlaO RESPECTO A OTRAS CIUdAdES DE LATINOAMÉRICA / HÉCTOR GUILlERMo GAMERo MotTA

\section{Imágenes}

Tabla 1. de OMS (1999). Efectos críticos sobre la salud según el tipo de ambiente. [Tabla]. En Guías para el ruido urbano (p. 12). Londres, Reino Unido.

Tabla 2. Ghotbi et al. (2011). Tiempo de exposición permitido para niveles de ruido según diferentes estándares internacionales. [Tabla]. En Noise pollution survey of a two-storey intersection station in Teheran metropolitan subway system. Environmental Monitoring and Assessment-Springer, 184: 1097-1106. DOI: 10.1007/s10661-011-2024-8

Tabla 3: OEFA (2015). Estándares de Calidad Ambiental para ruido en el Perú por zona de aplicación. [Tabla]. En Instrumentos básicos para la fiscalización ambiental (p. 26).

Tabla 4. WHO (2018). Valores de ruido límite recomendados por la OMS en función a la fuente. [Tabla]. En Environmental Noise Guidelines for the European Region (pp. xvi y xviii). Copenhague, Dinamarca.

Tabla 5. Posada (2018). Parque automotor del Perú en 2016. [Tabla]. En Aumento continuo del parque automotor, un problema que urge solucionar (p. 25). Cámara de Comercio de Lima.

Tabla 6: OEFA (2016). Resultados de los 10 puntos de mayor nivel de presión sonora en Lima. [Tabla]. En La contaminación sonora en Lima y Callao (p. 37).

Tabla 7. OEFA (2016). Resultados de los 10 puntos de mayor nivel de presión sonora en el Callao. [Tabla]. En La contaminación sonora en Lima y Callao (p. 51).

Tabla 8. Ministerio del Medio Ambiente de Chile (2011). Niveles máximos permisibles de presión sonora corregidos en Chile. [Tabla]. En DS 146/97 y DS 38/11. Consideraciones en el SEIA (p. 51).

Tabla 9. Casas, O., Betancur, C., Montaño, J. (2015). Estándares máximos permisibles de niveles de ruido en Colombia. [Tabla]. En Revisión de la normatividad para el ruido acústico en Colombia y su aplicación (p. 267).

Figura 1. INEI (2014). Ordenamiento territorial de Lima Metropolitana. [Tabla]. En Una mirada a Lima Metropolitana (p. 9).

Figura 2: OEFA (2016). Cantidad de puntos de medición por tipo de zona de aplicación que exceden los ECA de ruido en Lima. En La contaminación sonora en Lima y Callao (p. 36).

Figura 3. OEFA (2016). Mapa de isófonas de Lima Centro. En La contaminación sonora en Lima y Callao (p. 39).

Figura 4. OEFA (2016). Mapa de isófonas de Lima Este. En La contaminación sonora en Lima y Callao (p. 40).

Figura 5. OEFA (2016). Mapa de isófonas de Lima Norte. En La contaminación sonora en Lima y Callao (p. 41). 
Figura 6. OEFA (2016). Mapa de isófonas de Lima Sur. En La contaminación sonora en Lima y Callao (p. 42).

Figura 7. OEFA (2016). Cantidad de puntos de medición por tipo de zona de aplicación que exceden los ECA de ruido en Callao. En La contaminación sonora en Lima y Callao (p. 49).

Figura 9. Ministerio del Medio Ambiente de Chile (2014: 9). Pilares de la gestión del control de ruido en Chile. En Estrategia para la gestión del control de ruido ambiental (2010-2014) (p. 9).

Figura 10. Ministerio del Medio Ambiente de Chile (2016: s/p). [Mapa]. Mapa de ruido del Gran Santiago Urbano-Horario diurno. Línea mapas de ruido. https://ruido.mma.gob.cl/mapas-de-ruido/

Figura 11. MMA Chile (2016: s/p). [Mapa]. Mapa de ruido del Gran Santiago Urbano-Horario nocturno. Línea mapas de ruido. https://ruido.mma.gob. cl/mapas-de-ruido/

Figura 12. Casas, O., Betancur, C., Montaño, J. (2015). Mapa de ruido de BogotáHorario diurno. En Revisión de la normatividad para el ruido acústico en Colombia y su aplicación (p. 274).

Figura 13. Casas, O., Betancur, C., Montaño, J. (2015). Mapa de ruido de BogotáHorario nocturno. En Revisión de la normatividad para el ruido acústico en Colombia y su aplicación (p. 274). 